Published in "International Journal of Management and Decision Making", 2020, vol. 19, no 3, pp. 267-311, which should be cited to refer to this work.

DOI : 10.1504 / IJMDM. 2020.10024632

\title{
Dairy market selection approach using MCDM methods: A case of Iranian dairy market
}

\author{
Shervin Zakeri ${ }^{1 *}$, Mohammad Reza Rostamian Delavar ${ }^{2}$, Naoufel Cheikhrouhou ${ }^{3}$ \\ $I^{*}$ Department of Industrial Engineering, Islamic Azad University of Arak, Arak, Iran. \\ ${ }^{2}$ School of Industrial Engineering and Management (ITM), KTH Royal Institute of Technology, Stockholm, Sweden. \\ ${ }^{3}$ Geneva School of Business Administration, HES-SO, University of Applied Sciences Western Switzerland, Geneva, Switzerland \\ ${ }^{*}$ Corresponding Author \\ Shervin.zakeri@live.com
}

\begin{abstract}
Making the right decision on selecting a specific market has a strategic importance for a dairy company. The issue is viewed as a multi-criteria decision-making problem. The paper addresses the development of a multi-criteria decision making procedure including a pattern extraction from success and failure of current market introduction to generate logical framework for target market selection. The procedure uses Grey systems to deal fwith uncertainly and develops Technique for Order of Preference by Similarity to Ideal Solution and COmplex PRoportional Assessment to deal with the decision making. In addition of covering the gap of comprehensive research in Iran's domestic dairy market, the main problem this paper tries to solve is the selection of a target market which covers not only the limitations of the company's current markets but also holds their advantages. Therefore, the proposed approach is constructed on selecting the best potential market which possesses the company's best market's criteria and has less similarity to the company's worst market where the company sells its products. A real-world implementation of the approach is done within a dairy company located in Iran. Considering Tehran, the North, Khuzestan, and West Azerbaijan as the company's current market, and also Mashhad, Isfahan, Shiraz, and Tabriz as the company's potential market, Shiraz selected as the best target market through analysis of the population, the level of income, the per capita consumption, local brands, distance from the closest DC, and competitors as the selection criteria. Results show that considering current markets has a big influence on the market ranking procedure.
\end{abstract}

Key words: Market selection; Dairy market; Multi-criteria decision-making; Iranian dairy markets

\section{Introduction}

As a strategy, market segmentation involves with the division of a large market into segments of consumers with different needs, characteristics, or behavior which might require separate marketing policies (Liu et al., 2019). As a statistical process, market segmentation analysis is the process of grouping consumers into naturally existing or artificially created segments of consumers who share similar product preferences or characteristics (Dolnicar et al.,2018). Market segment evaluation can help in targeting markets, thus it is very important for improving the probability of success in competitive market (Aghdaie et al., 2013). It is then necessary to identify the most profitable segments (target market) and to decide which segments will be served (Dolnicar et al., 2018). Different approaches of the market segment evaluation can be found in (Liu et al. 2019; Dolnicar et al. 2018; Tian et al. 2018; Sarti et al. 2018; Wu et al. 2018; Aghdaie et al., 2013).

Target market selection is crucial marketing activities of all companies, which is a vital component of market development because it can help companies target their markets and improve their success (Ou, et al., 2009). Due to many feasible alternatives and conflicting objectives, selecting an appropriate target market is one of the most complicated and time-consuming problems for many companies. As the heart of various marketing decisions such as market mix selection, procurement, supply chain, and the distribution channels, market targeting involves some steps, so that the attractiveness of each market segment is firstly assessed and then one (more) segment is selected to enter which is the output of market segment evaluation and selection decision (Aghdaie \& Alimardani., 2015). As indicated by the National Commission on Agriculture (XII Report, 1976), starting with a decision, agricultural marketing including food marketing is a process that produces a saleable farm commodity, and it involves all the aspects of market structure or system, both functional and institutional, respecting to the technical and economic considerations, and also includes pre-and post-harvest operations, assembling, grading, storage, transportation, and distribution.

The Dairy industry stands as one of the most important food industries which is supplying many kinds of products such as yogurts, milk, cheeses, powdery products, beverages, creams, etc., which are supplied either by domestic dairy factories or by importation. As Imam et al, (2011) reported, since 1980 the demand for the dairy products grew especially in Asian region from $32 \mathrm{~kg}$ per capita in 1981 to $64 \mathrm{~kg}$ per capita in 2007, the Asian consumers presented almost a half of the world demand for milk and milk products. As such, lately, in Iran, the dairy industry has grown significantly. It is one of the most important loops of the agricultural food chain and agroindustry that has the first rank in the market and added value among the other agricultural industries (FOZOUNI et al., 2017). Before the US sanctions, the local institutes reported that there are more than 100 active companies in the country which produce a variety of dairy products from yogurt and cheese to milk-based desserts. The needs of raw milk are supplied from 
domestic farms, and the main export destinations are Iraq and Afghanistan. One of the first industries which affect by US sanctions was the domestic dairy industry. US sanctions caused a reduction in dairy products production (approximately \%30) and export reduction and have reduced foreign investments in the food and dairy industry. The reports of this paper are arranged before the US sanctions.

This paper intends to present a mathematical algorithm to select the priority of best potential dairy products markets by employing the grey system theory and also attempts to suggest some improvement in TOPSIS ${ }^{1}$ algorithm. The main question of the research is how to select a target market which has to cover the limitations of the current markets while holding the advantages of them. Moreover, the sub-questions are the following: 1. How the competitors can impact on the selection of markets? 2. Which criteria is more effective on the prioritization and selection of markets? and 3. How to connect the current markets analysis to target market selection?

In this paper following processes is performed: 1 . analysis of current markets; 2 . analysis of potential markets; 3 . identifying the target markets; 4. selection of the target market. The current paper is organized into seven sections. We follow a brief introduction to market selection approaches with introducing the dairy company's effectiveness in section 2 . Next, in section 3 , methodology and selecting algorithm development is described, then the model for selecting dairy companies is proposed. In the following section, statistical results are provided. The discussion is provided in section 6 . Finally, the managerial implications has been argued in section 7 amd the overall conclusions are discussed in section 8 .

\section{Literature Review}

According to Thomsen (1956), the study of agricultural marketing comprises all the operations, and the agencies conducting them, involved in the movement of farm-produced foods, raw materials and their derivatives, such as textiles, from the farms to the final consumers, and the effects of such operations on farmers, middlemen and consumers. The structure of agriculture markets and a market selection has become a major issue as the companies involved have grown larger, which has been discussed in previous studies (Burlakoti and Rajbhandari, 2016; Karthikeyan, 2016; Schmidt et al., 2016; Golijan, and Popović., 2016; Agbo et al., 2015). Conducted from January to May 2015, Burlakoti and Rajbhandari (2016) study assess marketing opportunities of IPM grown produce in Rupandehi and Nawalparasi districts. Focusing on the Indian farmers, Karthikeyan (2016) shows the problems including lack of finance, the large number of middlemen, transportation and storage facilities, grading and standardization, branding, price fluctuation, lack of market information faced by the farmers in the marketing of agriculture goods. Schmidt et al, (2016) provide a qualitative assessment of farmer and staff perceptions of successful practices and limitations. Golijan, and Popović (2016) analyzes organic areas, food production and the state of organic product markets, and the distribution channels as the economic factors and market trends of organic products at the global level. To study market structure where firms both cooperate and compete with each other, Agbo et al, (2015) propose a theoretical model in their study.

Furthermore, the following studies have been done in the dairy market: Bojnec and Fertö (2014) investigated the export competitiveness of dairy products of the European Union countries. John et al, (2015) compared Smallholder participation in maize, kale and milk markets in Kenya, and they found Land, assets, technology, prices, and rainfall are important to market participation. Jia et al, (2014) show the evolving of the Chinese dairy industry and dairy marketing after China's 2008 milk scandal and the impact of China government policies on the industry. Other studies can be mentioned as (Grau and Hockmann, 2018; Hansen and Li, 2017; Bolotova, (2016); Pinior, et al., 2012; Cakir and Balagtas, 2010; Stukenberg and Blayney,2006; Barney and Smith, 1998; Marchant and Neff, 1995).

There is very little published information regarding the dairy industry and dairy marketing in Iran. Recent studies can be addressed as (Bazham et al., 2018; Bazhan et al.,2017; Rahnama and Rajabpour,2017; FOZOUNI et al., 2017). Rahnama and Rajabpour (2017) investigated the effective indicators on the consumer purchasing decision-making process toward dairy products. To analyze the process, they used a structural equation modeling and found that functional values, social value, emotional value, and epistemic value have a positive impact on the purchasing dairy products and conditional value didn't have a positive impact in the country. FOZOUNI et al, (2017) studied Iran's dairy industry focusing on the provinces in terms of dairy industry development. They analyzed the current situation of Iran's dairy industry by determining the specific indices including the number of milk livestock, amount of raw milk production, milk price in the market, the number of active milk processing units, the total production of liquid milk, yogurt, cheese, Doogh and ice cream. Bazham et al.,(2018) and Bazhan et al.,(2017) studied dairy Iran's market and analyzed the dairy products' domestic marketplace.

As it is shown, the optimal procedure and algorithm for selecting a dairy companies' market have not been addressed in previous researches, which can gain more profit to companies and costumes. Indeed, the most important limitations of the research was the lack of clear information and statistical data. We had to cover these lacks with direct interviews, field researches and questionnaire forms. Another limitation was the lack of studies about the market selection and market selection indices. However, with analyses of the current situation of Iran's dairy market and the market's main players, the main contribution of this research is to propose an optimal decision-making algorithm for dairy companies with considering the comprehensive condition to select the most appropriate markets. To achieve this goal, we proposed an integrated MCDM algorithm using grey systems theory. MCDM problem is characterized by the ratings of each alternative with respect to each criterion and the weights given to each criterion (Xiao et al.2012). It ranks the feasible alternatives and selects the most desirable one(s) by considering multiple criteria, which are frequently in conflict with each other (Zakeri \& Keramati.2015; Zhang et al.2011). Also, grey theory (GT) is widely utilized in fields of

\footnotetext{
${ }^{1}$ Technique for Order of Preference by Similarity to Ideal Solution
} 
research, such as systems analysis, data processing, modeling, and prediction, as well as in control and decision-making (Zakeri \& Keramati.2015; Zhang et al., 2013; Deng, 1985; Bozoun, et al., 2017). In the case of MCDM application in the market evaluation process, the role of uncertainty concept can be found in (Liu et al. 2019; Dolnicar et al. 2018; Tian et al. 2018; Aghdaie et al., 2013). Dealing with $\mathrm{AHP}^{2}$ and TOPSIS, (Aghdaie \& Alimardani., 2015) proposed a hybrid method using AHP for extracting weight of criteria and TOPSIS for ranking target markets. To evaluate target market, they used complexity, knowledge, risk, probability, competition, sustainability, accessibility, homogeneity, suppliers' ability, and size and growth rate per year. Analogous to the previous work (Aghdaie \& Alimardani., 2015), in a case of chair manufacturing company, (Aghdaie et al., 2013) used COPRAS-G to rank the target markets, while Fuzzy AHP employed to tackle the need for evaluation of data to determine each criterion weight. In a fuzzy environment, they exploited McDonald and Dunbar's (2004) criteria list to evaluate the target markets including Segment factors (size, growth rate per year, sensitivity to price, service features and external factors, cyclicality, seasonality, bargaining power of upstream suppliers, and bargaining power of downstream suppliers as the sub-criteria), Competition (types of competitors, degree of concentration, changes in type and mix, entries and exits, changes in share, substitution by new technology, and degrees and types of integration as the sub-criteria), Financial and economic factors (contribution margins, leveraging factors, barriers to entry or exit (financial and non-financial), and capacity utilization as the subcriteria), Technological factors (maturity and volatility, complexity, differentiation, patents and copyrights, manufacturing process technology required as the sub-criteria), and Socio-political factors (social attitudes and trends, laws and government agency regulations, influence with pressure groups and government representatives, human factors as the sub-criteria). In this paper, grey theory has been used when only partial information is available with the decision maker, and linguistic variables are used to give weights to the criteria and ratings to the different alternatives, which is later on converted into grey numbers (see section 3.2). To evaluate the target market, aforementioned criteria (from previous studies) has been modified for the current study and used in the different steps of the proposed approach.

\section{Method and tools}

To select the most appropriate dairy market, an integrated MCDM approach had been proposed. In this section, MCDM, grey relation model and systems theory, Shannon's entropy, COPRAS-G and grey TOPSIS have been described.

\subsection{Multiple criteria decision making}

As Zakeri (2019) argued, when we talk about MCDM, or multi-criteria decision analysis, or even multi-attribute decision making (MADM) problems, we refer to a matrix-form problem with a set of alternatives which are supposed to be prioritized; that is, a set of criteria which is used to analyze alternatives. When evaluating a set of alternatives faces with multiple criteria many complex problems emerge such as weights of criteria, preference dependence, and conflicts among criteria; thus, to overcome the aforesaid problems, sophisticated methods need to be employed (Antoniou \& Aretoulis. 2018). Multiple criteria decision making (abbreviated to $\mathrm{MCDM}$ ) is a branch of operational research dealing with finding optimal results in complex scenarios including various indicators, conflicting objectives and criteria. This tool is becoming popular in the field of location selection due to the flexibility it provides to the decision makers to take decisions while considering all the criteria and objectives simultaneously. Ranking of classification algorithms normally need to examine several criteria, such as accuracy, computational time, and misclassification rate thus the selection algorithm can be modeled as MCDM problems (Peng et al.2012; Peng et al.2009; Rokach.2010). A typical MCDM problem consists of a number of alternative which rank via a number of criteria. The analysis process performs by the math algorithms called MCDM methods. We used MCDM and grey relation model as a market selection approach for dairy companies.

\subsection{Grey relation model}

In many situations, the preference information on attributes is uncertain and inconsistent (Khodaverdi \& Hashemi. 2015). Moreover, during the decision-making process, the decision makers attempt to gather as much information as possible through surveys, investigations, sampling, etc., so as to reach the aspired decision, but obtaining all the information remains impossibility, then, decisions are usually made in grey process, i.e. without complete information, this is where Grey Relation Analysis (GRA) finds application in solving MADM problems (Sahu et al; 2015). GRA reflects uncertainty into the multi-attribute model, where the reference number sequence is utilized instead of the ideal solution (Wu. 2006). The Grey System Theory (GT) was first introduced by (Deng.1989, 1990). According to the levels of information, GT includes three categories of uncertainty: the white, grey and the black.

The grey number of $\otimes G$ has two bound where $(G)$ is the lower bound $(\bar{G})$ is the upper bound therefore $\otimes 0 G=[\underline{G} \cdot \bar{G}]$, then:

$\otimes G=[\underline{G} \cdot \bar{G}]=\{G \mid \underline{G} \leq G \leq \bar{G} \cdot \underline{G}$ and $\bar{G} \in R\}$

The aforementioned equation denotes that the grey number is characterized by having insufficient and uncertain information (Zakeri and Keramati, 2015). The number without any meaningful information is called the black number where $\underline{x} \rightarrow-\infty$ and $\bar{x} \rightarrow+\infty$.

The $\otimes x$ is the white number if $\underline{x}=\bar{x}$ which means it is the complete information.

There are four possibilities for the emergence of grey information (lin et al., 2004):

(1) The information about elements is grey;

(2) The structural information is grey;

(3) The boundary information is grey; or,

(4) The behavior information of motion is grey.

\footnotetext{
${ }^{2}$ Analytic Hierarchy Process
} 
As Zavadskas et al., (2009) stated, the GRA possesses some advantages: 1. it involves simple calculations and requires a smaller number of samples; a typical distribution of samples is not needed. 2. the quantified outcomes from the grey relational grade do not result in contradictory conclusions to qualitative analysis. 3. the grey relational grade model is a transfer functional model that is effective in dealing with discrete data.

Following equations (Eq.2-10) address the grey number operations (Zakeri et al., 2019):

$$
\begin{aligned}
& \text { If } \otimes G_{1}=\left[\underline{G_{1}} \cdot \overline{G_{1}}\right], \otimes G_{2}=\left[\underline{G_{2}} \cdot \overline{G_{2}}\right] \text {, and } \overline{G_{1}}>\underline{G_{1}} \text { and } \overline{G_{2}}>\underline{G_{2}} \text {, then: } \\
& -\otimes G_{1}=\left[\overline{-G_{1}} \cdot-\underline{G_{1}}\right] \\
& \otimes G_{1}+\otimes G_{2}=\left[\underline{G_{1}}+\underline{G_{2}} \cdot \overline{G_{1}}+\overline{G_{2}}\right] \\
& \otimes G_{1}-\otimes G_{2}=\otimes G_{1}+\left(-\otimes G_{2}\right)=\left[\underline{G_{1}}-\overline{G_{2}} \cdot \overline{G_{1}}-\underline{G_{2}}\right] \\
& \otimes G_{1} \times \otimes G_{2}=\left[\min \left\{\underline{G_{1}} \underline{G_{2}} \cdot \underline{G_{1}} \overline{G_{2}} \cdot \overline{G_{1}} \underline{G_{2}} \cdot \overline{G_{1}} \overline{G_{2}}\right\} \cdot \max \left\{\underline{G_{1}} \underline{G_{2}} \cdot \underline{G_{1}} \overline{G_{2}} \cdot \overline{G_{1}} \underline{G_{2}} \cdot \overline{G_{1}} \overline{G_{2}}\right\}\right] \\
& r \times \otimes G_{1}=\left[r \underline{G_{1}} \cdot r \overline{G_{1}}\right] \\
& \otimes G_{1} / \otimes G_{2}=\left[\underline{G_{1}} \cdot \overline{G_{1}}\right] \times\left[\underline{\frac{1}{G_{2}}} \cdot \frac{1}{\overline{G_{2}}}\right]=\left[\underline{G_{1}} \cdot \overline{G_{1}}\right] \times\left[\underline{G_{2}^{-1}} \cdot \overline{G_{2}^{-1}}\right] \\
& =\left[\min \left\{\underline{G_{1}} \underline{G_{2}^{-1}} \cdot \underline{G_{1}} \overline{G_{2}^{-1}} \cdot \overline{G_{1}} \underline{G_{2}^{-1}} \cdot \overline{G_{1}} \overline{G_{2}^{-1}}\right\} \cdot \max \left\{\underline{G_{1}} \underline{G_{2}^{-1}} \cdot \underline{G_{1}} \overline{G_{2}^{-1}} \cdot \overline{G_{1}} \underline{G_{2}^{-1}} \cdot \overline{G_{1}} \overline{G_{2}^{-1}}\right\}\right]
\end{aligned}
$$

The possibility degree of $\otimes G_{1} \leq \otimes G_{2}$ is in accordance with (Eq.10)

$p\left\{\otimes G_{1} \leq \otimes G_{2}\right\}=\frac{\max \left(0 . L^{*}-\max \left(0 . \underline{G_{1}}-\overline{G_{2}}\right)\right)}{L^{*}}$

where $L^{*}=L\left(\otimes G_{1}\right)+L\left(\otimes G_{2}\right)$

\subsection{Shannon's Entropy}

One of the major results of information theory is the Shannon entropy (Shannon.2001). In MCDM problems, to analyze decision matrices, this method has been widely employed to extract the weight of each criterion from the decision matrix. According to the (Das et al.2014) the grey entropy is as (Eq.11,12):

$$
\begin{aligned}
& e_{\underline{G}_{j}}=-\frac{1}{\ln m} \sum_{i=1}^{m} \underline{G}_{i j} \ln \underline{G}_{i j} \\
& e_{\bar{G}_{j}}=-\frac{1}{\ln m} \sum_{i=1}^{m} \bar{G}_{i j} \ln \bar{G}_{i j}
\end{aligned}
$$

The weight of $J$ th creation is as Eq.(13;14):

$w_{\underline{G}_{j}}=1-e_{\underline{G}_{j}}\left(\sum_{j=1}^{n}\left(1-e_{\underline{G}_{j}}\right)\right)^{-1}$
$w_{\bar{G}_{j}}=1-e_{\bar{G}_{j}}\left(\sum_{j=1}^{n}\left(1-e_{\bar{G}_{j}}\right)\right)^{-1}$

3.4. COPRAS-G (Complex Proportional Assessment- Grey)

The COmplex PRoportional ASsessment (COPRAS) method first developed by Zavadskas and Kaklauskas (1994). Description of COPRAS methods and possibilities of its application are widely utilized in researches (Das et al.,2012; Zavadskas et al., 2001; Vilutiene and Zavadskas, 2003; Zavadskas et al., 2004; Kaklauskas et al., 2005; Kaklauskas et al., 2006; Zavadskas et al., 2008). The original COPRAS algorithm is carried out as the following steps (Mulliner.2016):

The weighted normalized decision matrix (Eq.15):

$\hat{x}_{i j}=\frac{q_{i}}{\sum_{j=1}^{n} x_{i j}} \cdot x_{i j} ; \quad i=1 . . . m ; j=1 . \ldots . n$; 
Where $\left(q_{i}\right)$ stands for the weight of $i$ th criterion, the $\left(x_{i j}\right)$ expresses the value of the $i$ th of the $j$ th alternatives, $(n)$ denotes the number of alternatives, and $(m)$ uses as the number of attributes in the algorithm. The sum of dimensionless weighted index values $\left(\hat{x}_{i j}\right)$ of each criterion is always equal to the significance $\left(q_{i}\right)$ of this criterion (Nuuter et al., 2015):

$q_{i}=\sum_{j=1}^{n} \hat{x}_{i j} ; \quad i=1 . . . m ; \quad j=1 . \ldots . n ;$

The alternatives are described by maximizing "benefit" attributes $S_{+j}$ and minimizing "cost" attributes $S_{-j}$ Sums are computed as following equations (Eq.17,18):

$S_{+j}=\sum_{i=1}^{m} \hat{x}_{+i j} ; \quad i=1 . . . m ; \quad j=1 . . . n$;

$S_{-j}=\sum_{i=1}^{m} \hat{x}_{-i j} ; \quad i=1 \ldots . . . m ; \quad j=1 . \ldots . n ;$

The significance of the comparative alternatives is computed in the third step on the basis of describing of benefit $(+)$ and cost $(-)$ qualities which characterize the alternatives. The relative significance $\left(Q_{i}\right)$ of each alternative $a_{j}$ is computed as (Eq.19;19*):

$Q_{j}=S_{+j}+\frac{S_{-\min } \cdot \sum_{j=1}^{n} S_{-j}}{S_{-j} \cdot \sum_{j=1}^{n} \frac{S_{-\min }}{S_{-j}}} ; j=1 . \ldots n$;

or

$Q_{j}=S_{+j}+\frac{\sum_{j=1}^{n} S_{-j}}{S_{-j} \cdot \sum_{j=1}^{n} \frac{1}{S_{-j}}} ; \quad j=1 . \ldots . n ;$

The alternative with the highest relative significance $\left(Q_{j}\right)$ is considered as the best alternative and according to (Zavadskas et al; $2009)$ in the case of $\left(Q_{\max }\right)$ the satisfaction degree is the highest.

The final step is the calculation of the utility degree of each alternative according to the following equation:

$N_{j}=\frac{Q_{j}}{Q_{\max }} \cdot 100 \%$

The COPRAS-G algorithm is as following as (Zavadskas et al;2009):

Selection of the set of the most important criteria, describing the alternatives.

Construction of the decision matrix $\otimes X$ :

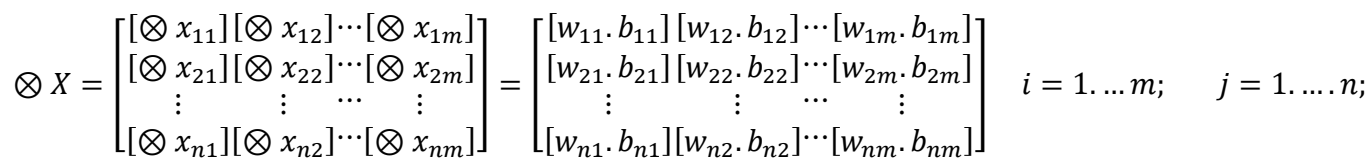

Where $\left(w_{j i}\right)$ is the upper bound and $\left(b_{j i}\right)$ is the lower bound of $\left(\otimes x_{i j}\right)$.

Computation of the weights of the criteria $\left(q_{i}\right)$.

Next step is normalizing of the matrix $(\otimes X)$ :

$\underline{w_{j i}}=\frac{w_{j i}}{\frac{1}{2}\left(\sum_{j=1}^{n} w_{j i}+\sum_{j=1}^{n} b_{j i}\right)}=\frac{2 w_{j i}}{\sum_{j=1}^{n} w_{j i}+\sum_{j=1}^{n} b_{i j}} ; \quad i=1 \ldots m ; \quad j=1 \ldots . . n$;

$\overline{b_{j i}}=\frac{b_{j i}}{\frac{1}{2}\left(\sum_{j=1}^{n} w_{j i}+\sum_{j=1}^{n} b_{j i}\right)}=\frac{2 b_{j i}}{\sum_{j=1}^{n}\left(w_{j i}+b_{j i}\right)} ; \quad i=1 . . . m ; \quad j=1 . \ldots n$;

Where $(m)$ is the number of criteria and $(n)$ is the number of the alternatives thus normalized matrix is as follow:

$\otimes \hat{X}=\left[\begin{array}{cccc}{\left[\underline{w_{11}} \cdot \overline{b_{11}}\right]} & {\left[\underline{w_{12}} \cdot \overline{b_{12}}\right]} & \ldots & {\left[\underline{w_{1 m}} \cdot \overline{b_{1 m}}\right]} \\ {\left[\underline{w_{21}} \cdot \overline{b_{21}}\right]} & {\left[\underline{w_{22}} \cdot \overline{b_{22}}\right]} & \ldots & {\left[\underline{w_{2 m}} \cdot \overline{b_{2 m}}\right]} \\ \vdots & \vdots & \cdots & \vdots \\ {\left[\underline{w_{n 1}} \cdot \overline{b_{n 1}}\right]} & {\left[\underline{w_{n 2}} \cdot \overline{b_{n 2}}\right]} & \cdots & {\left[w_{n m} \cdot \overline{b_{n m}}\right]}\end{array}\right]$

The next step is the determination of the weighted normalized decision matrix $(\otimes \hat{X})$ therefore the weighted normalized values $\left(\otimes \hat{x}_{j i}\right)$ will be computed as following equation: 
$\otimes \hat{x}_{j i}=\left[\widehat{w}_{j i} \cdot \hat{b}_{j i}\right] ; \quad \widehat{w}_{j i}=w_{j i} \cdot q_{i} ; \quad \hat{b}_{j i}=\overline{b_{j i}} \cdot q_{i}$

where $\left(q_{i}\right)$ is the weight of $i$ th criterion. To calculate the sums $\left(P_{j}\right)$ of the attribute values, the higher (larger) values are more preferable and for the calculation of the $\left(R_{j}\right)$ of the attribute values, the lower (smaller) are more preferable either. Hence, the $\left(R_{j}\right)$ and $\left(P_{j}\right)$ have been computed as the following equations:

$P_{j}=\frac{1}{2} \sum_{i=1}^{k}\left(\widehat{w}_{j i}+\widehat{b}_{j i}\right)$

$R_{j}=\frac{1}{2} \sum_{i=k+1}^{k}\left(\widehat{w}_{j i}+\hat{b}_{j i}\right) ; \quad i=k \cdot m ;$

Determination of minimal value of $R_{j}$ is the next step of COPRAS-G algorithm.

$R_{j}=\min _{j} R_{j} ; \quad j=1 . \ldots . n$;

After determination of the minimal value of $R_{j}$, the relative weight of each alternative must be calculated. The calculation is as the following equation where the $\left(Q_{j}\right)$ is the relative weight of each alternative.

$Q_{j}=P_{j}+\frac{\sum_{j=1}^{n} R_{j}}{R_{j} \sum_{j=1}^{n} \frac{1}{R_{j}}}$

The next step is the determination of the optimality criterion, where $K$ is the optimality criterion.

$K=\max _{j} Q_{j} ; \quad j=1 \ldots . . n$;

The eleventh step is the prioritization of the alternatives. And the final step is the computation of the utility degree of each alternative respecting to the (Eq.31):

$N_{j}=\frac{Q_{j}}{Q_{\max }} \cdot 100 \%$

Where the $\left(Q_{j}\right)$ and $\left(Q_{\max }\right)$ are the weight of projects obtained from (Eq.29).

\subsection{The grey TOPSIS}

To solve the MCDM problems, Hwang and Yoon (1981) developed a technique for establishing order performance by referencing its similarity to the ideal solution (TOPSIS). The basis for the technique's concept is that the selected alternative's value should have the shortest distance from the positive ideal (Azimuth) solution and the farthest distance from the negative ideal (Nadir) solution (Certa et al. 2018; Dymova et al.2013). The grey TOPSIS are as following steps (Zakeri \& Keramati.2015):

Step 1. Constructing the decision matrix.

Step 2. Establishing the normalized decision matrices with respect to the cost or benefit as following as the $(E q .32,33)$

For benefit attribute of $\left(\otimes G_{i j}^{*}\right)$, the normalization process is defined as (Eq.32):

$\otimes G_{i j}^{+}=\left[\frac{G_{i j}}{G_{j}^{\text {max }}} \cdot \overline{\overline{G_{i j}}} \overline{G_{j}^{\text {max }}}\right]$

Where $\otimes G_{i j}=\left[\underline{G_{i j}}, \overline{G_{i j}}\right]$ and $\otimes G_{j}^{\max }=\max _{1 \leq i \leq m}\left\{\overline{G_{l j}}\right\}$

And for a cost attribute of $\otimes G_{i j}^{*}$, there is following equation:

$\otimes G_{i j}^{-}=\left[\frac{G_{j}^{\min }}{\overline{G_{i j}}} \cdot \frac{G_{j}^{\text {min }}}{G_{i j}}\right]$

Where $\otimes G_{j}^{\max }=\min _{1 \leq i \leq m}\left\{\overline{G_{l}}\right\}$

Step 3. Construction of the weighted normalized matrix.

Step 4. Calculation of $\left(S^{\max }\right)$ as the ideal alternative where $\left(S^{\max }\right)$ is a referential alternative by following equations (Eq.34,35):

$S^{\max }=\left\{G_{1}^{\max } \cdot G_{2}^{\max } \cdot G_{3}^{\max } \ldots . . G_{n}^{\max }\right\}$

$S^{\max }=\left\{\left[\max _{1 \leq i \leq m} \underline{V_{i 1}} \cdot \max _{1 \leq i \leq m} \overline{V_{i 1}}\right] \ldots .\left[\max _{1 \leq i \leq m} \underline{V_{i n}} \cdot \max _{1 \leq i \leq m} \overline{V_{i n}}\right]\right\} ;$

Step 4. Computation of the distance between each of the alternatives sequences as following as (Eq.36):

$d=\Delta_{\otimes G_{1}-\otimes G_{2}}=\left(\underline{G_{1}}-\underline{G_{2}}\right)+\left(\overline{G_{1}}-\overline{G_{2}}\right)$

Where $\triangle$ stands for the distance $(d)$ between two grey numbers of $\left(\otimes G_{1}\right)$ and $\left(\otimes G_{2}\right)$.

Step 5. Determination of the grey relation coefficient of each alternative with the respect to the (Eq.37): 
$\gamma_{o i}=\gamma\left(x_{o}(j) \cdot x_{i}(j)\right)=\frac{\min _{i} \min _{j} d_{i j}+\xi \max _{i} \max _{j} d_{i j}}{d_{i j}+\xi \max _{i} \max _{j} d_{i j}}$

Step 6. Computing the grade of the grey relation of each alternative compared to the ideal solution in accordance with (Eq.38):

$C_{i}=\left(1-\frac{1}{n} \cdot \sum_{j=1}^{n} \gamma_{i j}\right) \quad i=1 . \ldots . m$

Step 6 . The final step is the prioritization of the alternatives. The higher score of $\left(C_{i}\right)$ has the priority.

\section{The Proposed Model}

In the case of an Iranian dairy company, this paper intends to propose a math algorithm to select the most attractive market to sell dairy products. In respect of the nature of dairy products, the population density implies the customer density. Accordingly, as a rule of thumb, the population density categorized as the positive criteria in market selection in the opposite of geographic diversification. Nonetheless, some brands solve this problem by increasing the number of distribution centers (DC)s in geographical zones or extending their transportation systems. The potential sale in a geographic area indicates the attractiveness of the market. Predominantly, there are specific criteria for evaluation of the attractiveness of markets. One of the most important indicators is consumption per capita. In general, the area with more population presages the more density of prospects. On the other hand, the area with more consumption per capita characterizes the higher level of consumption per person. Another criterion which is used in this paper to assess the market attractiveness is the consumers' culture. As Shavitt and Cho (2015) stated, consumer behavior encompasses a broad range of phenomena, and cultural factors have been shown to influence many of them. Culture shapes what general goals consumers have, and how they respond to prices, brand image and advertising elements (Shavitt et al., 2016). Furthermore, in different regions, people may commit to a local brand and avoid shopping from other brands which are prevalent in Iran's markets.

The income level of customers is another indicator which has been investigated in this paper. The customers with a high level of income go after the luxury products with a higher price; in the opposite, the customers with a lower level of income tend to buy the lower cost products; e.g. in the city of Tehran, the propensity to buy the luxury products in the northern areas is more than the southern areas. Hence, the level of income is another criterion which determines the attractiveness of the market to select the market. The proposed methodology's stages have been illustrated in (Fig 1):

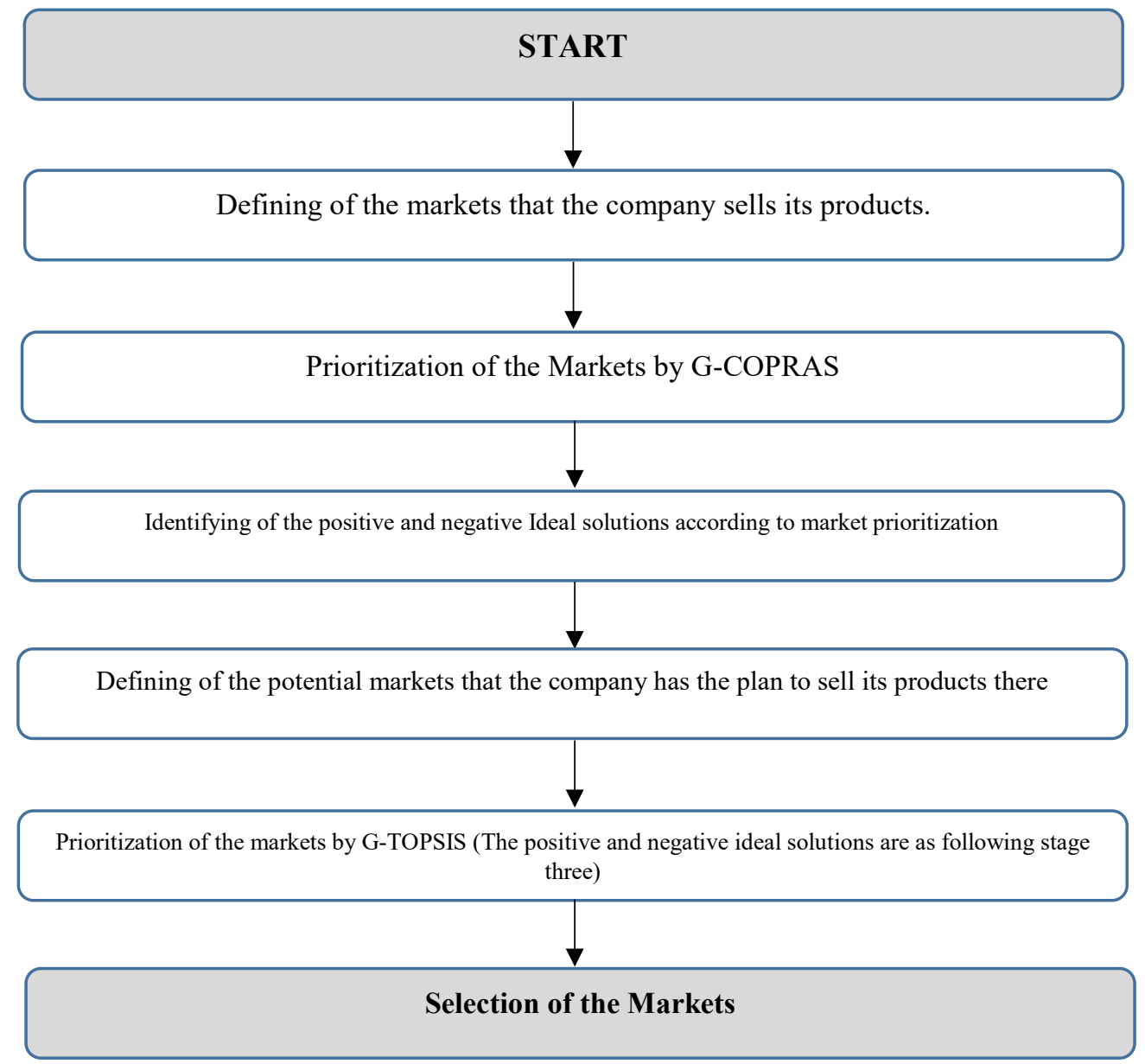


Fig.1.The methodology algorithm

The proposed approach is presented in the five stages. The procedures of stages compose an integrated approach for selecting the best market. Following contents portray each stage procedure and their connections and interactions.

Stage.1: the first stage of the proposed method is the definition of the markets where the company sells its products there. The market details have been designated in this stage. It helps to understand the market's indices which the company sells its products there.

Stage.2: in this stage, the markets have been prioritized by COPRAS-G. There are various MCDM techniques that can be candidate to use for the multiple criteria assessment of alternatives; e.g. as the popular MCDM techniques: COPRAS (A Method of Multiple Criteria Proportional Assessment), EVAMIX (Evaluation of Mixed Data), TOPSIS, VIKOR (VI`sekriterijumsko KOmpromisno Rangiranje), AHP, etc. In Chatterjee and Athawale (2011) compared these methods, and highlighted advantages of different approaches. The mentioned comparison has been declared in (Table 1).

Table 1

Performance of some multiple criteria evaluation methods

\begin{tabular}{cccccc}
\hline Method & Calculation time & Simplicity & Transparency & Possibility of graphical interpretation & Information type \\
\hline COPRAS & Less & Very simple & Very good & Very high & Quantitative \\
EVAMIX & Moderate & Moderately critical & Reasonable & Low & Mixed \\
TOPSIS & High & Moderately critical & Good & Low & Quantitative \\
VIKOR & Less & Simple & Reasonable & Good & Quantitative \\
AHP & Very high & Very critical & Low & Mixed \\
\hline
\end{tabular}

As revealed in the aforementioned table, regarding the simplicity and less computational time of COPRAS, this method has been employed for the selection of the market. Moreover, Moreover, Nuuter et al, (2015) have described the reason for choosing the COPRAS method: the method has noticeable advantages among the other methods, the very short calculation time, easy implementation for any program source code same as VIKOR, understanding and result checking is very common and computation results can be easily visualized and interpreted. To overcome the unnecessary environmental problems such as decision maker's (DM's) decisions or some criteria which described as the interval, (e.g. distance or the number of sales), the proposed approach deal with GT. In GT operations, the attributes are defined as the numerical intervals. As the grey COPRAS method, COPRAS-G has been cited in the third section of this paper.

Stage.3: after prioritization of the markets, respectively, the $1^{\text {st }}$ rank and the last rank assume as the positive and negative ideal solution of the TOPSIS algorithm. The advantage of this method is that it gives the feasibility to the company to select that new markets which supply its sales requirements, the requirements which company is well-familiar with them. In fact, the markets where the company sells its product there has the minimum standards of company's sales requirements and the new selected markets will be on the spectrum between the best and worst markets that company sells the products there. The 1st rank as the positive ideal shows the ideal market with the most of ideal indices, while the last priority means the market with the less ideal indices, however, it is still the standard market for sells requirements.

Stage.4: For prioritization and selection of the markets, the market's indices must be identified. Definition of the potential markets is performed in the fourth stage. In this paper, the prioritization process is in accordance with the markets' indices that they are closer to the current markets' indices.

Stage.5: In this stage, the markets prioritization performs via G-TOPSIS. As discussed earlier, TOPSIS method selects the alternatives which are located on the shortest distance from the ideal solution and the farthest distance from the negative ideal solution, whereas, with respect to the G-TOPSIS algorithm, G-TOPSIS does not predict the negative ideal solution in its algorithm (see Eq.34, 35). To apply the G-TOPSIS to our method with the negative and positive ideal solution, (Jadidi et al; 2009) proposed the improved G-TOPSIS with positive and negative ideal referential alternatives to compare the priority of grey numbers. This paper utilized the aforesaid improved method to select the most desirable market. According to the (Jadidi et al;2009), the ideal and negative ideal referential market can be obtained from (Eq.39,40):

$S^{\max }=\left\{\left[\max _{1 \leq i \leq m} \underline{G_{i 1}^{*}} \cdot \max _{1 \leq i \leq m} \overline{G_{i 1}^{*}}\right] \ldots .\left[\max _{1 \leq i \leq m} \underline{G_{i n}^{*}} \cdot \max _{1 \leq i \leq m} \overline{G_{i n}^{*}}\right]\right\}$

$S^{\min }=\left\{\left[\min _{1 \leq i \leq m} \underline{G_{i 1}^{*}} \cdot \min _{1 \leq i \leq m} \overline{G_{i 1}^{*}}\right] \ldots\left[\min _{1 \leq i \leq m} \underline{G_{i n}^{*}} \cdot \min _{1 \leq i \leq m} \overline{G_{i n}^{*}}\right]\right\}$

where $S^{\max }=\left\{G_{1}^{\max } \ldots . . G_{n}^{\max }\right\}$ and $S^{\min }=\left\{G_{1}^{\min } \ldots . G_{n}^{\min }\right\}$ are the positive and negative ideal referential respectively. Hence, the weighted connection between each of the alternatives sequence and the referential sequence is computed as following equation: 
$\Gamma_{i}=\frac{1}{n} \sum_{j=1}^{n}\left(\left(\frac{\left|G_{j}^{\text {max }}-G_{i j}^{*}\right|}{\left|G_{j}^{\text {max }}-G_{j}^{\text {min }}\right|}\right) \times W_{j}\right)$

where $\left(W_{j}\right)$ stands for the weight of attribute. When $\left(\Gamma_{i}\right)$ is the smallest, the ranking order of $\left(S_{i}\right)$ is the best, otherwise the ranking order is the worst. Thus, in the proposed approach, as the output of the G-TOPSIS, the smallest value of $\left(\Gamma_{i}\right)$ selects as the best potential market.

\section{Real world application and results}

In this section, the application of the new approach of a dairy company and its results are presented. To achieve this purpose, a dairy company located in Iran is considered. The company aims to select the most appropriate potential market to sell its product.

5.1. defining the current markets

The company's current markets comprise following provinces: Tehran, North of Iran, Khuzestan, Hormozgan and West Azerbaijan. The North includes the provinces of (Guilan, Mazandaran and Golestan). The markets have been displayed in (Fig 2):

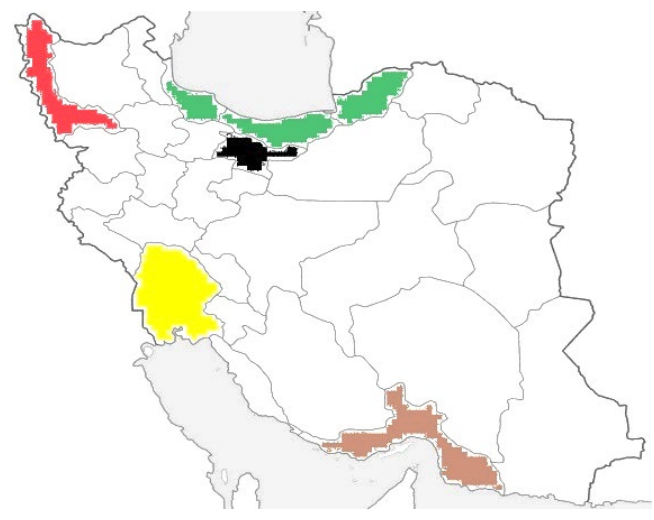

Fig.2.The current markets: Hormozgan, Khuzestan, West Azerbaijan, Tehran and the North marked as the brown, yellow red, black and the green color respectively.

In this paper, the markets' ranking process performs through the following criteria analysis: 1 . the tendency to local brands; 2 . The number of competitors; 3 . distance from the closest DC; 4. the population; 5. the Per capita consumption; 6. the Rate of income; and 7. the consumers' palate; The three company's DCs feed its current markets. The geographical locations of the DCs have been illustrated in the following map:

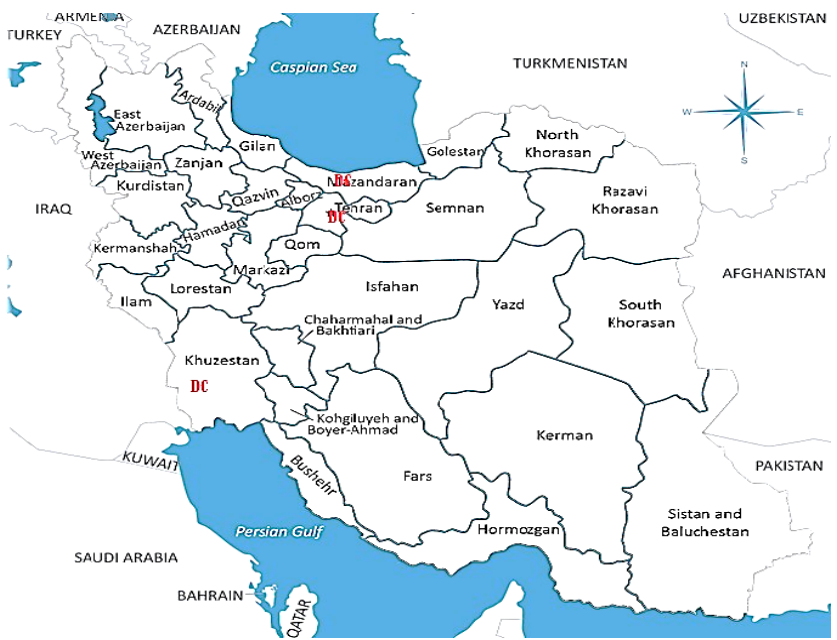

Fig.3.The company's three DCs are located in Khuzestan (Ahvaz), Tehran (Tehran) and the North (Amol city)

The aforementioned criteria have been expressed in the grey numbers. It means that each criterion has been exposed as an interval with two bounds (limitations). The tables marked with two bounds of grey numbers where $(\otimes \underline{G})$ is the lower and the $(\otimes \bar{G})$ shows the upper bound. The content of tables such as population and level of income are referred from the last census of Statistical Center of Iran. 
Table 2

the population

\begin{tabular}{lcc}
\hline The Current Markets & $\otimes \underline{G}$ & $\otimes \bar{G}$ \\
\hline Tehran & 2772287 & 3069941 \\
The North & 1978168 & 2174172 \\
Khuzestan & 1549453 & 1700687 \\
West Azerbaijan & 1545491 & 1695094 \\
\hline
\end{tabular}

As revealed in (Table 2), as the lower bound, $(\otimes \underline{G})$ remarks the population of the province center, and as the upper bound $(\otimes \bar{G})$ is the population of the province. These two bounds specify the interval (in terms of population) that the company can meet the market needs. In fact, the coverage of the sales is a "number" between the province center as the minimum and the whole population of the province as the maximum sales' coverage. As mentioned heretofore, in this case, the north includes three provinces. Hence, the minimum coverage is the total population of the three provinces center (Rasht, Sari, Gorgan for Guilan, Mazandaran and Golestan respectively) and the upper bound is the total population of the three provinces. The level of income for the current markets have been demonstrated in (Table 3):

Table 3

the level of income

\begin{tabular}{lcc}
\hline The Current Markets & $\otimes \underline{G}$ & $\otimes \bar{G}$ \\
\hline Tehran & 132282970 & 285990000 \\
The North & 105651502.6 & 188207333.3 \\
Khuzestan & 105748849 & 225614000 \\
West Azerbaijan & 89945378 & 157915000 \\
\hline
\end{tabular}

The philosophy of the bounds selection is according to the people's income in four years. The lower bound exhibits the income in 2010 and the upper bound is the income in 2014 (according to the latest statistics provided by the Statistics Center), where the currency is Iranian rial. The reason that Iranian rial is chosen over the US dollar is the inflation rate and the currencies fluctuation between these two years. Along to the four years, dollar value almost reached three times than Iranian rial then Iranian rial lost its value 3 times. Even after relative economic stability in 2014 to 2017, the level of income did not change too much (which is signally changed after the late US sanctions in 2018). Today, in accordance with our field studies, the maximum and minimum income is very close to the given information (Table 3 ). The per capita consumption is as following table:

Table 4

the per capita consumption $(\mathrm{Kg})$

\begin{tabular}{lcc}
\hline The Current Markets & $\otimes \underline{G}$ & $\otimes \bar{G}$ \\
\hline Tehran & 88 & 93 \\
The North & 88 & 92 \\
Khuzestan & 83 & 86 \\
West Azerbaijan & 77 & 81 \\
\hline
\end{tabular}

In Iran, for each province, there are no provided certain statistics for per capita consumption of dairy products. Therefore, to collect data, the questionnaire forms have been used. In (Table 4), the exposed information is the results of the questionnaire analysis, and the bounds are the minimum and maximum of consumer consumption. For example, the given information about Tehran explains that the per capita consumption is between $88 \mathrm{~kg}$ and $93 \mathrm{~kg}$.

As the result of our field studies, the tendency to the local brands has been shown in Fig.4. To achieve the mentioned result, the research process started with the questionnaire forms; then, in the next step, the number of local brands investigated. In the research, local brands are the SME(s) or they have been named after the non-industrial dairy products which have been produced in the nonindustrial conditions by the local people. As one of the results of our research, a direct connection between the tendency to local brands and the local culture, and also between tendencies to local brands with the number of local brands is detected. But, there was a paradox in the results. According to the direct interview with 107 people from various regions of the city (Tehran's 22 municipal districts) and 1100 questionnaire forms analysis, unlike the other cities, while Tehran has the highest number of the local brands, we found that the lowest orientation to local brands is in there. The number of local brands has been demonstrated in (Table 5):

Table 5

the number of local brands

\begin{tabular}{lc}
\hline The Current Markets & Number of local brands \\
\hline Tehran & 48 \\
The North & 32 \\
Khuzestan & 24 \\
West Azerbaijan & 43 \\
\hline
\end{tabular}

With analysis the connection between "the tendency to local brands" and "the number of local brands" as the output of the questionnaire forms analysis, and eke the results of interviews, all results have been imported to the grey intervals (Table 4). The cited information is extracted from (Fig 4) which is a new scale of rating attribute for local brands where "the attributes" have been determined based on the number of local brands. 


\begin{tabular}{|c|c|c|c|c|c|c|}
\hline [16. 25] & {$[25.28]$} & [28.31] & [31.34] & [34.37] & [37. 42] & {$[42.50]$} \\
\hline & $T$ & 1 & $T$ & 1 & T & \\
\hline VP & $P$ & MP & $\mathrm{F}$ & MG & $\mathrm{G}$ & VG \\
\hline
\end{tabular}

Fig.4. the scale of rating attribute

In (Fig 4), respectively, the corresponding grey values for "Very Poor (VP)", "Poor (P)", "Medium Poor (MP)", "Fair (F)", "Medium Good (MG)", "Good (G)", and "Very Good (VG)" are [0, 1], [1, 3], [3, 4], [4, 5], [5, 6], [6, 9], [9, 10]. As mentioned previously, in Tehran, the tendency to local brands is in the lowest level. Thus, its corresponding scale is VP (see Table 6):

\section{Table 6}

the attribute of rating of the local brands in the current markets

\begin{tabular}{lc}
\hline The Current Markets & $\otimes G$ \\
\hline Tehran & VP \\
The North & $\mathrm{F}$ \\
Khuzestan & VP \\
West Azerbaijan & VG \\
\hline
\end{tabular}

The next criterion which has been investigated is the distance from the closest DC. As illustrated in (Fig 3), the company's three DCs are located in Tehran, Amol, and Ahvaz. Google map has been utilized to calculate the distances. For each city where the DCs are located there, two regions have been chosen as the concepts of intervals where the company covers the market. The maximum distance form DC has been as the upper bound, while the minimum distance has been delegated as the lower bound (see Table 7).

Table 7

distance from the closest DC

\begin{tabular}{cccc}
\hline \multirow{2}{*}{ The current Market } & The Closest DC & $\otimes \underline{G}$ & $\otimes \bar{G}$ \\
\cline { 3 - 4 } & & $\begin{array}{c}\text { Distance of the closest DC from } \\
\text { the city (K/M) }\end{array}$ & $\begin{array}{c}\text { Distance of the closest DC from } \\
\text { the city (K/M) }\end{array}$ \\
\hline Tehran & Tehran & 51.8 & 148.9 \\
Khe North & Amol & 208.3 & 321 \\
West Azerbaijan & Ahvaz & 140 & 142.1 \\
\hline
\end{tabular}

The number of competitors is the another criterion for the company's current market analysis. In the analysis process, nine main competitors of the company have been selected. The competitors are as following list: 1. Kalleh; 2. Pegah; 3. Damdaran; 4. Sabbah; 5. Choupan; 6. Pajan; 7. Ramak; 8. Alis; and 9. Apadana. Following table presents the number of the competitors in the market in an interval of nine years from 2008 to 2017.

Table 8

the number of competitors in the years of 2008-2017.

\begin{tabular}{|c|c|c|}
\hline \multirow[b]{2}{*}{ The Current Markets } & $\otimes \underline{G}$ & $\otimes \bar{G}$ \\
\hline & 2008 & 2017 \\
\hline Tehran & 8 & 9 \\
\hline The North & 4 & 6 \\
\hline Khuzestan & 5 & 7 \\
\hline West Azerbaijan & 4 & 5 \\
\hline
\end{tabular}

In this paper, to count the competitors, the market presence of these nine have been investigated. For instance, in 2017 all of the competitors had a share of the market in Tehran. With respect to the markets, the displayed information in (Table 9) shows the market shares that each competitor possesses in 2008-2017.

Table 9

the competitors' presence in markets

\begin{tabular}{|c|c|c|c|c|c|c|c|c|}
\hline \multirow{3}{*}{$\begin{array}{c}\text { The } \\
\text { Competitors }\end{array}$} & \multicolumn{8}{|c|}{ The current Markets } \\
\hline & \multicolumn{4}{|c|}{2008} & \multicolumn{4}{|c|}{2017} \\
\hline & Tehran & The North & Khuzestan & $\begin{array}{c}\text { West } \\
\text { Azerbaijan }\end{array}$ & Tehran & The North & Khuzestan & $\begin{array}{c}\text { West } \\
\text { Azerbaijan }\end{array}$ \\
\hline Kalleh & $\bullet$ & $\bullet$ & $\bullet$ & $\bullet$ & - & $\bullet$ & $\bullet$ & - \\
\hline Pegah & - & • & • & • & • & • & • & • \\
\hline Damdaran & • & • & - & - & - & • & • & • \\
\hline Sabbah & • & & & & • & • & - & • \\
\hline Choupan & $\bullet$ & & & & $\bullet$ & & & \\
\hline
\end{tabular}




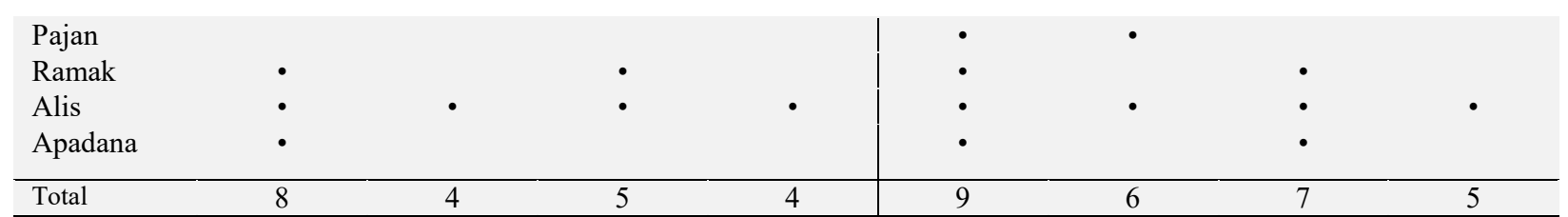

5.1.1. Ranking procedure of competitors

As it exposed in (Table 9), there are two different data in two years of 2008 and 2017. In this paper, we suppose the years as the two bounds of a numerical interval where the year of 2008 is the lower bound $(\otimes \underline{G})$ and 2017 is the upper bound $(\otimes \bar{G})$ of the grey number. In the market, there is a significant difference between the competitor, which must be considered. This paper proposed a simple algorithm to devote the main role to competitors in the selection process of the best market by consideration of the competitors' current and potential impact on the prioritization and selection. The algorithm is depicted in (Fig 5):

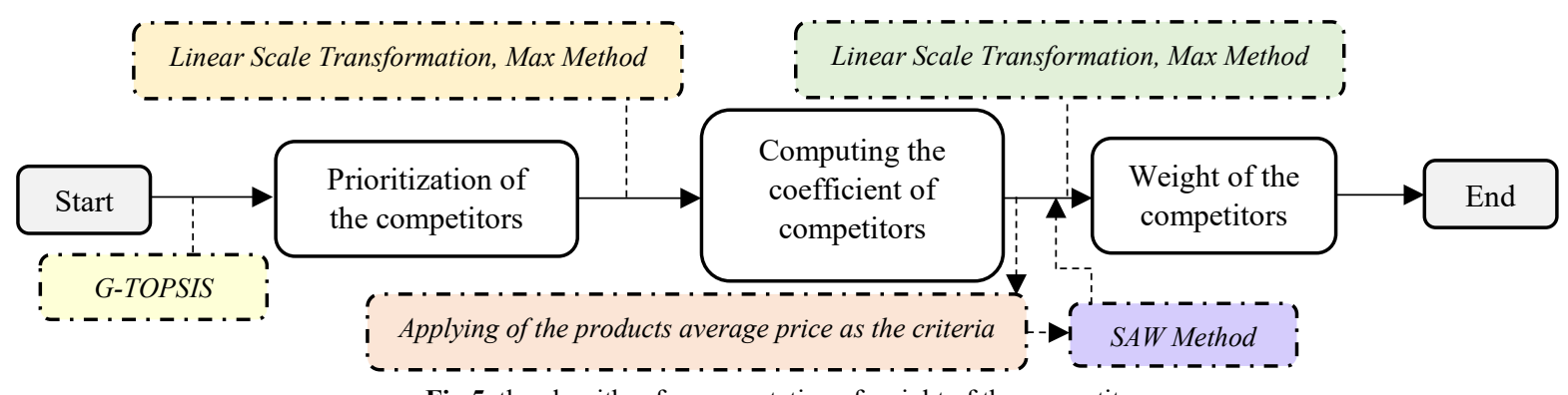

Fig.5. the algorithm for computation of weight of the competitors

With using G-TOPSIS method, the prioritization of the competitors executes respecting to the four general indices of the brand prioritization. According to (Bazhan et al.,2017; FOZOUNI et al., 2017) and our field study, parameters with the most influence on the dairy market are as follows: 1. Product Desirability (Quality); 2. Brand Awareness; 3. Power of Investment; and 4. Product Availability, which are assumed as the criteria in G-TOPSIS algorithm. Additionally, Shannon's entropy is employed to calculate the weights of criteria. The following table shows the attribute rating of each criterion.

Table 10

the attribute of rating of the competitors

\begin{tabular}{|c|c|c|c|c|}
\hline & Product desirability (Quality) & Brand awareness & Power of investment & Product availability \\
\hline Kalleh & F & $\mathrm{G}$ & VG & VG \\
\hline Pegah & $\mathrm{P}$ & G & G & G \\
\hline Damdaran & G & G & MG & $\mathrm{F}$ \\
\hline Sabbah & MP & $\mathrm{F}$ & G & F \\
\hline Choupan & MG & F & F & MP \\
\hline Pajan & $\mathrm{F}$ & MP & F & MP \\
\hline Ramak & F & MG & MG & $\mathrm{P}$ \\
\hline Alis & F & MG & MG & $\mathrm{G}$ \\
\hline Apadana & MG & $\mathrm{P}$ & MP & $\mathrm{P}$ \\
\hline
\end{tabular}

In accordance with Shannon's entropy (Eq.11-14), the weight of each criterion is displayed in (Table 11).

Table 11

Entropy and the raw weight of each criteria

\begin{tabular}{lcccccccc}
\hline & \multicolumn{2}{c}{ Product desirability (Quality) } & \multicolumn{2}{c}{ Brand awareness } & \multicolumn{2}{c}{ Power of investment } & \multicolumn{2}{c}{ Product availability } \\
\hline$e_{j}$ & 1.3546 & 1.1720 & 1.2729 & 0.8745 & 1.2933 & 0.98706 & 1.1941 & 1.16896 \\
$d_{j}$ & -0.3546 & -0.1720 & -0.2729 & +0.8745 & -0.2933 & -0.98706 & -0.1941 & -0.16896 \\
$\lambda_{j}$ & & 0.3 & \multicolumn{2}{c}{0.2} & & 0.25 & 0.25 \\
$w_{j}$ & 0.11284 & 0.15149 & 0.057874 & 0 & 0.7778 & 0.72448 & 0.05147 & 0.124 \\
\hline
\end{tabular}

where

$d_{j}=1-e_{j}$

In the aforementioned table, $\left(\lambda_{j}\right)$ is the DMs' decisions as the experts. According to (Eq.6), following equations demonstrate the impact of DMs' decisions on the final weight.

$w_{\underline{G}_{j}}=\left(\lambda_{j}\right)\left(1-e_{\underline{G}_{j}}\right)\left(\sum_{j=1}^{n}\left(\lambda_{j}\right)\left(1-e_{\underline{G}_{j}}\right)\right)^{-1}$ 
$w_{\bar{G}_{j}}=\left(\lambda_{j}\right)\left(1-e_{\bar{G}_{j}}\right)\left(\sum_{j=1}^{n}\left(\lambda_{j}\right)\left(1-e_{\bar{G}_{j}}\right)\right)^{-1}$

In line with (Eq.42), the set of $\left(w_{j}\right)$ has been transferred to the crisp numbers:

$W_{j}=\left(w_{\underline{G_{j}}}+w_{\overline{G_{j}}}\right)\left(\sum_{j=1}^{n} w_{\underline{G_{j}}}+w_{\overline{G_{j}}}\right)^{-1}$

Consequently, the final weights are shown in (Table 12).

Table 12

the final weight of each criteria

\begin{tabular}{|c|c|c|c|c|}
\hline & Product desirability (Quality) & Brand awareness & Power of investment & Product availability \\
\hline$w_{j}$ & 0.132 & 0.0289 & 0.751 & 0.0877 \\
\hline
\end{tabular}

In respect to the Grey TOPSIS algorithm (Eq.32-38) ranking of the competitors is as following results (see Table 13), where the value of $(\xi)$ is 0.5 and the linear scale transformation of the max method is in line with (Eq.46) :

$n_{i j}=1-\frac{r_{i j}}{r_{i j}^{*}}$

Where

$r_{i j}^{*}=\max _{i} r_{i j}$

and $\left(n_{i j}\right)$ is the linear scale transformation of the max method.

Table 13

ranking and coefficient of competitors

\begin{tabular}{lccc}
\hline The Competitors & Grey Relation & Rank & Weight of the competitors \\
\hline Kalleh & 0.022250 & 1 & 0.88889 \\
Pegah & 0.109820 & 2 & 0.77778 \\
Sabbah & 0.118600 & 3 & 0.66667 \\
Damdaran & 0.122100 & 4 & 0.55556 \\
Alis & 0.135100 & 5 & 0.44444 \\
Choupan & 0.141300 & 6 & 0.33333 \\
Pajan & 0.149950 & 7 & 0.22222 \\
Ramak & 0.157650 & 8 & 0.11111 \\
Apadana & 0.181620 & 9 & 0.00001 \\
\hline
\end{tabular}

To calculate the weight of each competitor, the cost of products has been exploited as another criterion. The cost has been investigated in the three groups of products comprising the cheese, yoghurts and the beverages as the most consumed dairy products in Iran (Bazhan et al;2017). The ranking table is revealed in (Table 14), where (+) is the benefit and (-) shows the cost attributes:

Table 14

Normalized decision matrix of competitors ranking

\begin{tabular}{|c|c|c|c|c|}
\hline $\begin{array}{l}w_{J} \\
\text { The Competitors }\end{array}$ & $\begin{array}{c}0.025 \\
- \\
\text { Beverages Price }\end{array}$ & $\begin{array}{c}0.05 \\
- \\
\text { Cheese Price } \\
\end{array}$ & $\begin{array}{c}0.05 \\
- \\
\text { Yoghurts Price }\end{array}$ & $\begin{array}{c}0.875 \\
+ \\
\text { Coefficient }\end{array}$ \\
\hline Kalleh & 0.77778 & 0.88889 & 0.88889 & 0.88889 \\
\hline Pegah & 0.55556 & 0.66667 & 0.66667 & 0.77778 \\
\hline Sabbah & 0.66667 & 0.77778 & 0.77778 & 0.66667 \\
\hline Damdaran & 0.88889 & 0.88889 & 0.88889 & 0.55556 \\
\hline Alis & 0.88889 & 0.00001 & 0.00001 & 0.44444 \\
\hline Choupan & 0.88889 & 0.88889 & 0.88889 & 0.33333 \\
\hline Pajan & 0.88889 & 0.00001 & 0.88889 & 0.22222 \\
\hline Ramak & 0.77778 & 0.77778 & 0.88889 & 0.11111 \\
\hline Apadana & 0.66667 & 0.66667 & 0.77778 & 0.00001 \\
\hline
\end{tabular}

The final ranking has been computed through SAW method. The SAW (Simple Additive Weighting) method is probably the simplest, best-known and most commonly used MCDM method (Wang et al., 2016). The SAW method uses a simple aggregation procedure (Stanujkic et al., 2013). In SAW, the overall score of a candidate solution is determined by the weighted sum of all attribute values (Wang et al.2016), the methodology of SAW is as following equation:

$Q_{i}=\sum_{j=1}^{n} W_{j} r_{i j}$

Where $\left(Q_{i}\right)$ is the ranking score of the $j$ th alternative, $\left(w_{j}\right)$ stands for the weight of the $j$ th criterion, and $\left(r_{i j}\right)$ expresses the normalized performance of the $i$ th alternative with respect to the $j$ th criterion. After applying the cost impact to the ranking process of the competitors, the final result has been illustrated in (Table 15): 
Table 15

The final ranking of the competitors and the final weight of them

\begin{tabular}{lccc}
\hline The Competitors & $Q_{i}$ & Rank & Final Weight \\
\hline Kalleh & 0.6694 & 1 & 0.88889 \\
Pegah & 0.600002 & 2 & 0.77778 \\
Sabbah & 0.48889 & 3 & 0.66667 \\
Damdaran & 0.375004 & 4 & 0.55556 \\
Alis & 0.366662 & 5 & 0.44444 \\
Choupan & 0.180553 & 6 & 0.33333 \\
Pajan & 0.127775 & 7 & 0.22222 \\
Ramak & 0 & 8 & 0.11111 \\
Apadana & 0 & 9 & 0.00001 \\
\hline
\end{tabular}

Respecting to (Table 8,$9 ; 15$ ), the following table demonstrates the grey weights of the competitors in the analysis process of the current market prioritization.

Table 16

the interval weight of the competitors

\begin{tabular}{lll}
\hline The Current Markets & $\otimes \underline{G}$ & $\otimes \bar{G}$ \\
\hline Tehran & 3.77779 & 4.00001 \\
The North & 2.77778 & 3.55556 \\
Khuzestan & 2.88889 & 3.44446 \\
West Azerbaijan & 2.77778 & 3.33334 \\
\hline
\end{tabular}

\subsection{Prioritization of the Markets by COPRAS-G}

The second section of the proposed approach is the prioritization of the current markets according to the provided results of the pervious section. As discussed in advance, the new approach deals with COPRAS-G method to rank the current markets. As the COPRAS-G outputs, the $1^{\text {st }}$ rank and the last rank have been employed as the best and worst ideal in the G-TOPSIS algorithm.

Table 17

decision matrix of the current markets

\begin{tabular}{lcccccc}
\hline & The population & the level of income & $\begin{array}{c}\text { the per capita } \\
\text { consumption }\end{array}$ & $\begin{array}{c}\text { Local } \\
\text { brands }\end{array}$ & $\begin{array}{c}\text { Distance from the } \\
\text { closest DC }\end{array}$ \\
\hline Tehran & {$[2772287,3069941]$} & {$[132282970,285990000]$} & {$[88,93]$} & {$[0,1]$} & {$[51.8,148.9]$} \\
The North & {$[1978168,2174172]$} & {$[105651502.6,188207333.3]$} & {$[88,92]$} & {$[4,5]$} & {$[208.3,321]$} \\
Khuzestan & {$[1549453,1700687]$} & {$[105748849,225614000]$} & {$[83,86]$} & {$[0,1]$} & {$[140,142.1]$} \\
West Azerbaijan & {$[1545491,1695094]$} & {$[89945378,157915000]$} & {$[77,81]$} & {$[9,10]$} & {$[764.9,789.9]$} & {$[2.777777,10,4.00001]$} \\
\hline
\end{tabular}

According to the method algorithm of COPRAS-G (Eq.21-31), the prioritization of the market is as following steps.

Step 1. In regard to (Eq. 22, 23), the normalized matrix is as following table:

Table 18

normalized decision matrix

\begin{tabular}{lcccccc}
\hline $\begin{array}{l}\text { The Current } \\
\text { Markets }\end{array}$ & The population & the level of income & $\begin{array}{c}\text { the per capita } \\
\text { consumption }\end{array}$ & $\begin{array}{c}\text { Local } \\
\text { brands }\end{array}$ & $\begin{array}{c}\text { Distance from } \\
\text { the closest DC }\end{array}$ & Competitors \\
\hline Tehran & {$[0.336,0.372]$} & {$[0.275,0.596]$} & {$[0.255,0.27]$} & {$[0.0 .066]$} & {$[0.0403,0.116]$} & {$[0.284,0.301]$} \\
The North & {$[0.24,0.264]$} & {$[0.22,0.392]$} & {$[0.255,0.267]$} & {$[0.266,0.333]$} & {$[0.162,0.25]$} & {$[0.21,0.267]$} \\
Khuzestan & {$[0.188,0.206]$} & {$[0.22,0.47]$} & {$[0.241,0.25]$} & {$[0,0.66]$} & {$[0.109,0.110]$} & {$[0.217,0.26]$} \\
West Azerbaijan & {$[0.187,0.205]$} & {$[0.187,0.329]$} & {$[0.224,0.235]$} & {$[0.6,0.666]$} & {$[0.596,0.615]$} & {$[0.21,0.267]$} \\
\hline
\end{tabular}

Step 2. Computation of the weights of the criteria $\left(q_{i}\right)$ by the Grey entropy (Eq.11-14, 43). The results are exhibited in (Table 19):

Table 19

Entropy and the weight of each criteria

\begin{tabular}{|c|c|c|c|c|c|c|c|c|c|c|c|c|}
\hline \multirow{2}{*}{$\begin{array}{l}\text { The Current } \\
\text { Markets } \\
e_{j}\end{array}$} & \multicolumn{2}{|c|}{ The population } & \multicolumn{2}{|c|}{ the level of income } & \multicolumn{2}{|c|}{$\begin{array}{l}\text { the per capita } \\
\text { consumption }\end{array}$} & \multicolumn{2}{|c|}{ Local brands } & \multicolumn{2}{|c|}{$\begin{array}{c}\text { Distance from the } \\
\text { closest DC }\end{array}$} & \multicolumn{2}{|c|}{ Competitors } \\
\hline & 0.964 & 0.988 & 0.963 & 1 & 0.991 & 1 & 0.622 & 0.855 & 0.703 & 0.821 & 0.563 & 1 \\
\hline$d_{j}$ & 0.036 & 0.012 & 0.037 & 0 & 0.009 & 0 & 0.378 & 0.145 & 0.297 & 0.179 & 0.437 & 0 \\
\hline$w_{j}$ & 0.03015 & 0.328 & 0.031 & 0 & 0.0075 & 0 & 0.3165 & 0.431 & 0.2487 & 0.532 & 0.366 & 0 \\
\hline$W_{j}$ & \multicolumn{2}{|c|}{0.1563} & \multicolumn{2}{|c|}{0.0135} & \multicolumn{2}{|c|}{0.0032} & \multicolumn{2}{|c|}{0.3263} & \multicolumn{2}{|c|}{0.3408} & \multicolumn{2}{|c|}{0.16} \\
\hline
\end{tabular}

Step 3. Construction of the weighted normalized decision matrix corresponding to (Eq.25):

Table 20

Weighted normalized decision matrix

\begin{tabular}{|c|c|c|c|c|c|c|}
\hline $\begin{array}{l}\text { The Current } \\
\text { Markets }\end{array}$ & The population & $\begin{array}{l}\text { the level of } \\
\text { income }\end{array}$ & $\begin{array}{l}\text { the per capita } \\
\text { consumption }\end{array}$ & Local brands & $\begin{array}{l}\text { Distance from } \\
\text { the closest DC }\end{array}$ & Competitors \\
\hline $\begin{array}{l}\text { Optimization } \\
\text { direction }\end{array}$ & $\max$ & $\max$ & $\max$ & $\min$ & $\min$ & $\min$ \\
\hline
\end{tabular}




\begin{tabular}{|c|c|c|c|c|c|c|c|c|c|c|c|c|}
\hline & \multicolumn{2}{|c|}{$\otimes G_{1}$} & \multicolumn{2}{|c|}{$\otimes G_{2}$} & \multicolumn{2}{|c|}{$\otimes G_{3}$} & \multicolumn{2}{|c|}{$\otimes G_{4}$} & \multicolumn{2}{|c|}{$\otimes G_{5}$} & \multicolumn{2}{|c|}{$\otimes G_{6}$} \\
\hline & $\otimes \underline{G_{1}}$ & $\otimes \overline{G_{1}}$ & $\otimes \underline{G_{2}}$ & $\otimes \overline{G_{2}}$ & $\otimes \underline{G_{3}}$ & $\otimes \overline{G_{3}}$ & $\otimes \underline{G_{4}}$ & $\otimes \overline{G_{4}}$ & $\otimes \underline{G_{5}}$ & $\otimes \overline{G_{5}}$ & $\otimes \underline{G_{6}}$ & $\otimes \overline{G_{6}}$ \\
\hline Tehran & 0.0525 & 0.0581 & 0.0037 & 0.0080 & 0.00081 & 0.00860 & 0.0000 & 0.0215 & 0.0137 & 0.0395 & 0.0454 & 0.0481 \\
\hline The North & 0.0375 & 0.0412 & 0.0029 & 0.0053 & 0.00081 & 0.00085 & 0.0868 & 0.1086 & 0.0552 & 0.0852 & 0.0336 & 0.0427 \\
\hline Khuzestan & 0.0293 & 0.0322 & 0.003 & 0.0063 & 0.00077 & 0.00080 & 0.0000 & 0.2153 & 0.0371 & 0.0375 & 0.0347 & 0.0416 \\
\hline West Azerbaijan & 0.0292 & 0.0320 & 0.0025 & 0.0044 & 0.00071 & 0.00075 & 0.1958 & 0.2173 & 0.2031 & 0.2095 & 0.0336 & 0.0427 \\
\hline
\end{tabular}

Step 4. According to (Table 21), the fourth step is dedicated to the calculation of the sums $\left(P_{j}\right)$ of the attribute values, the $\left(R_{j}\right)$ of the attribute values, the relative weight of alternatives $\left(Q_{j}\right)$, optimality criterion $(K)$, and the utility degree of alternatives $\left(N_{j}\right)$ in accordance with (Eq.26-31).

Table 21

evaluation of the utility degree and ranking of the current markets

\begin{tabular}{lcccc}
\hline The Current Markets & $P_{j}$ & $R_{j}$ & $Q_{j}$ & $N_{j}$ \\
\hline Tehran & 0.065855 & 0.0841 & 1.42587 & $100.000 \%$ \\
The North & 0.088560 & 0.4121 & 0.36620 & $25.6825 \%$ \\
Khuzestan & 0.036185 & 0.3662 & 0.34852 & $24.4426 \%$ \\
West Azerbaijan & 0.069560 & 0.9020 & 0.19630 & 3 \\
\hline
\end{tabular}

5.3. Identifying positive and negative ideal solutions according to market prioritization

As exposed in (Table 22), the $1^{\text {st }}$ rank of the current markets is Tehran and the last place belongs to West Azerbaijan. As discussed in advance, these two markets play the role of the $S^{\min }$ and $S^{\max }$ as the negative and positive ideal solutions in Grey TOPSIS process.

\subsection{Defining potential markets}

The company's potential markets are located in Mashhad, Isfahan, Shiraz and Tabriz. The potential markets are shown in (Fig 6):

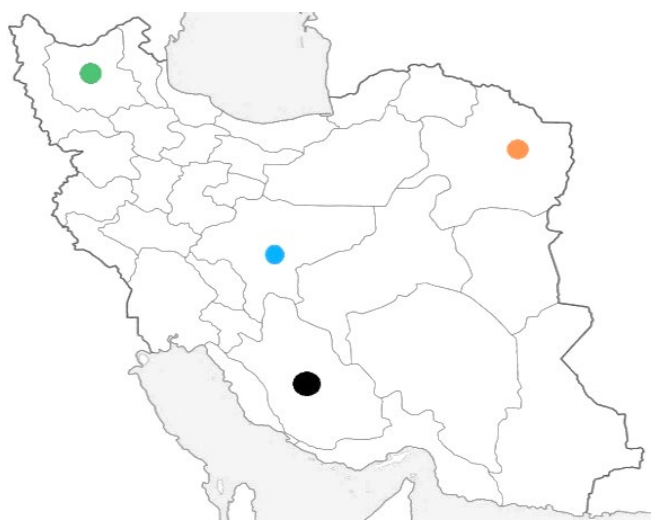

Fig.6.The potential Markets. The green is Tabriz, blue is Isfahan, the black is Shiraz and orange is Mashhad

According to stage.5.1 procedures, following tables (22-30) shows the information of the potential markets:

\subsubsection{The Population}

The population in the regions where the potential markets are located is revealed in (Table 22):

Table 22

the population

\begin{tabular}{lcc}
\hline The potential Markets & $\otimes \underline{G}$ & $\otimes \bar{G}$ \\
\hline Mashhad & 2772287 & 3069941 \\
Isfahan & 1978168 & 2174172 \\
Shiraz & 1549453 & 1700687 \\
Tabriz & 1545491 & 1695094 \\
\hline
\end{tabular}

The lower bound $(\otimes \underline{G})$ includes the urban population that the company can meet their needs and the upper bound $(\bar{G})$ consists of both rural and the urban population that the company is capable of meeting their needs.

\subsubsection{The Level of income}

The level of income has been described in (Table 23):

Table 23

the level of income

\begin{tabular}{lcc}
\hline The potential Markets & $\otimes \underline{G}$ & $\otimes \bar{G}$ \\
\hline Mashhad & 97429063 & 183912000
\end{tabular}




\begin{tabular}{lcc} 
Isfahan & 93390015 & 182231000 \\
Shiraz & 111740495 & 193411000 \\
Tabriz & 89345632 & 159690000 \\
\hline 5.4.3. The Per capita consumption &
\end{tabular}

The grey form of per capita in the potential markets have been stated in the following table:

Table 24

Per capita consumption

\begin{tabular}{lcc}
\hline The potential Markets & $\otimes \underline{G}$ & $\otimes \bar{G}$ \\
\hline Mashhad & 79 & 80 \\
Isfahan & 78 & 80 \\
Shiraz & 70 & 76 \\
Tabriz & 85 & 87 \\
\hline
\end{tabular}

5.4.4. The Number of brands

In line with (Fig 3) and (Table 25), the number of brands are displayed in (Table 26):

Table 25

the number of local brands

\begin{tabular}{lc}
\hline The potential Markets & $\bigotimes \underline{G}$ \\
\hline Mashhad & 25 \\
Isfahan & 31 \\
Shiraz & 17 \\
Tabriz & 38 \\
\hline
\end{tabular}

Table 26

the attribute of rating of the local brands in the potential markets

\begin{tabular}{lc}
\hline The potential Markets & $\otimes \underline{G}$ \\
\hline Mashhad & $\mathrm{P}$ \\
Isfahan & $\mathrm{MP}$ \\
Shiraz & $\mathrm{VP}$ \\
Tabriz & $\mathrm{G}$ \\
\hline
\end{tabular}

5.4.5. Distance from the closest DC

As exposed in (Table 27), to demonstrate the lower and upper bounds, two areas have been selected. The mentioned areas are the closest cities to the target markets (the potential markets) where the closest is the lower bound $(\otimes \underline{G})$ and the further is the upper bound $(\otimes \bar{G})$. It shows the market range (the interval) where the company has to cover.

Table 27

distance from the closest DC

\begin{tabular}{|c|c|c|c|c|c|c|}
\hline \multirow[b]{2}{*}{$\begin{array}{l}\text { The potential } \\
\text { Market }\end{array}$} & \multirow[b]{2}{*}{$\begin{array}{c}\text { The Closest } \\
\text { DC }\end{array}$} & \multirow[b]{2}{*}{$\begin{array}{c}\text { Geographical } \\
\text { coordinate of DC }\end{array}$} & \multirow[b]{2}{*}{$\begin{array}{c}\text { Geographical } \\
\text { coordinate of area }\end{array}$} & \multirow[b]{2}{*}{$\begin{array}{c}\text { Geographical } \\
\text { coordinate of area }\end{array}$} & $\otimes \underline{G}$ & $\otimes \bar{G}$ \\
\hline & & & & & $\begin{array}{l}\text { Distance of the } \\
\text { closest DC from } \\
\text { the city }(\mathrm{K} / \mathrm{M})\end{array}$ & $\begin{array}{l}\text { Distance of the } \\
\text { closest DC from } \\
\text { the city }(\mathrm{K} / \mathrm{M})\end{array}$ \\
\hline Mashhad & Amol & $\begin{array}{l}36^{\circ} 28^{\prime} 15^{\prime \prime} \mathrm{N} \\
52^{\circ} 21^{\prime} 48^{\prime \prime} \mathrm{E}\end{array}$ & $\begin{array}{l}\text { Chenaran } \\
35^{\circ} 42^{\prime} 26^{\prime \prime} \mathrm{N} \\
59^{\circ} 51^{\prime} 2^{\prime \prime} \quad \mathrm{E}\end{array}$ & $\begin{array}{c}\text { Fariman } \\
36^{\circ} 6^{\prime} 18^{\prime \prime} \mathrm{N} \\
59^{\circ} 10^{\prime} 31^{\prime \prime} \mathrm{E}\end{array}$ & 717.4 & 815.8 \\
\hline Isfahan & Tehran & $\begin{array}{l}35^{\circ} 40^{\prime} 19^{\prime \prime} \mathrm{N} \\
51^{\circ} 25^{\prime} 28^{\prime \prime} \mathrm{E}\end{array}$ & $\begin{array}{l}\text { Ardestan } \\
31^{\circ} 23^{\prime} 0^{\prime \prime} \mathrm{N} \\
54^{\circ} 22^{\prime} 0^{\prime \prime} \mathrm{E}\end{array}$ & $\begin{array}{l}\text { Shahreza } \\
32^{\circ} 2^{\prime} 2^{\prime \prime} \quad \mathrm{N} \\
51^{\circ} 52^{\prime} 46^{\prime \prime} \mathrm{E}\end{array}$ & 360 & 530.5 \\
\hline Shiraz & Ahvaz & $\begin{array}{l}31^{\circ} 19^{\prime} 45^{\prime \prime} \mathrm{N} \\
48^{\circ} 41^{\prime} 28^{\prime \prime} \mathrm{E}\end{array}$ & $\begin{array}{c}\text { Kazrun } \\
29^{\circ} 37^{\prime} 6^{\prime \prime} \mathrm{N} \\
51^{\circ} 39^{\prime} 30^{\prime \prime} \mathrm{E}\end{array}$ & $\begin{array}{c}\text { Fasa } \\
29^{\circ} 29^{\prime} 1^{\prime \prime} \mathrm{N} \\
52^{\circ} 38^{\prime} 26^{\prime \prime} \mathrm{E}\end{array}$ & 438.4 & 681.4 \\
\hline Tabriz & Tehran & $\begin{array}{l}35^{\circ} 40^{\prime} 19^{\prime \prime} \mathrm{N} \\
51^{\circ} 25^{\prime} 28^{\prime \prime} \mathrm{E}\end{array}$ & $\begin{array}{l}\text { Hashtrood } \\
34^{\circ} 53^{\prime} 16^{\prime \prime} \mathrm{N} \\
46^{\circ} 4^{\prime} 55^{\prime \prime} \quad \mathrm{E}\end{array}$ & $\begin{array}{l}\text { Shabestar } \\
38^{\circ} 11^{\prime} 2^{\prime \prime} \mathrm{N} \\
45^{\circ} 41^{\prime} 56^{\prime \prime} \mathrm{E}\end{array}$ & 523.7 & 694.8 \\
\hline
\end{tabular}

5.4.5. Number of Competitors

With respect to the (Table 17) and (Fig 5), the number of competitors is as following tables.

Table 28

the number of competitors in the years of 2013-2017.

\begin{tabular}{|c|c|c|}
\hline & $\otimes \underline{G}$ & $\otimes \bar{G}$ \\
\hline The potential Markets & 2008 & 2017 \\
\hline Mashhad & 5 & 7 \\
\hline Isfahan & 6 & 7 \\
\hline Shiraz & 4 & 6 \\
\hline Tabriz & 1 & 2 \\
\hline
\end{tabular}


Table 29

the competitors' presence in the markets

\begin{tabular}{|c|c|c|c|c|c|c|c|c|}
\hline \multirow{3}{*}{$\begin{array}{c}\text { The } \\
\text { Competitors }\end{array}$} & \multicolumn{8}{|c|}{ The current Markets } \\
\hline & \multicolumn{4}{|c|}{2008} & \multicolumn{4}{|c|}{2017} \\
\hline & Mashhad & Isfahan & Shiraz & Tabriz & Mashhad & Isfahan & Shiraz & Tabriz \\
\hline Kalleh & - & - & - & & - & - & - & - \\
\hline Pegah & - & - & - & - & - & - & - & - \\
\hline Damdaran & - & - & - & & - & - & - & \\
\hline Sabbah & - & & & & - & - & & \\
\hline Choupan & & & & & - & & & \\
\hline Pajan & & & & & - & & & \\
\hline Ramak & & - & & & & - & - & \\
\hline Alis & - & - & - & & - & - & - & \\
\hline Apadana & & & & & & - & - & \\
\hline Total & 5 & 5 & 4 & 1 & 7 & 7 & 6 & 2 \\
\hline
\end{tabular}

\section{Table 30}

Weights of the competitors

\begin{tabular}{lcc}
\hline The potential Markets & $\otimes \underline{G}$ & $\otimes \bar{G}$ \\
\hline Mashhad & 3.33334 & 3.88889 \\
Isfahan & 2.88889 & 3.55557 \\
Shiraz & 2.66667 & 2.8889 \\
Tabriz & 0.77778 & 1.66667 \\
\hline
\end{tabular}

5.5. Market selection procedure

As mentioned earlier, in this section, the potential markets have been prioritized by G-TOPSIS method respecting to the following steps.

Step 5.5.1. Constructing the decision matrix.

Table 31

decision matrix of the potential markets prioritization

\begin{tabular}{|c|c|c|c|c|c|c|}
\hline & + & + & + & - & - & - \\
\hline $\begin{array}{l}\text { The potential } \\
\text { Markets }\end{array}$ & The population & the level of income & the per capita & $\begin{array}{l}\text { Local } \\
\text { brands }\end{array}$ & $\begin{array}{l}\text { Distance from the } \\
\text { closest DC }\end{array}$ & Competitors \\
\hline Mashhad & {$[2772287,3069941]$} & {$[97429063,183912000]$} & {$[79,80]$} & {$[1,3]$} & {$[717.4,815.8]$} & {$[3.33334,3.88889]$} \\
\hline Isfahan & {$[1978168,2174172]$} & {$[93390015,182231000]$} & {$[78,80]$} & {$[3,4]$} & {$[360,530.5]$} & {$[2.88889,3.55557]$} \\
\hline Shiraz & {$[1549453,1700687]$} & {$[111740495,193411000]$} & {$[70,76]$} & {$[0,1]$} & {$[438.4,681.4]$} & {$[2.66667,2.8889]$} \\
\hline Tabriz & {$[1545491,1695094]$} & {$[89345632,159690000]$} & {$[85,87]$} & {$[6,9]$} & {$[523.7,694.8]$} & {$[0.77778,1.66667]$} \\
\hline
\end{tabular}

Where (+) and (-) describe the benefit and the cost attributes correspondingly.

Step.5.5.2. Establishing the normalized decision matrix (Table 32) with respect to (Eq.32,33). In this study, the basis of methodology is to select the best potential markets in accordance with the current markets. The weights of the criteria are extracted from (Table 19).

Table 32

the normalized decision matrix

\begin{tabular}{|c|c|c|c|c|c|c|}
\hline$W_{j}$ & 0.1563 & 0.0135 & 0.0032 & 0.3263 & 0.3408 & 0.16 \\
\hline $\begin{array}{l}\text { The potential } \\
\text { Markets }\end{array}$ & $\begin{array}{c}+ \\
\text { The population }\end{array}$ & $\begin{array}{c}\quad+ \\
\text { the level of income }\end{array}$ & $\begin{array}{c}\quad+ \\
\text { the per capita }\end{array}$ & $\begin{array}{c}- \\
\text { Local } \\
\text { brands }\end{array}$ & $\begin{array}{l}- \\
\text { Distance from } \\
\text { the closest DC }\end{array}$ & Competitors \\
\hline Mashhad & {$[0.903,1]$} & {$[0.504,0.951]$} & {$[0.908,0.919]$} & {$[0.333,1]$} & {$[0.441,0.502]$} & {$[0.2,0.233]$} \\
\hline Isfahan & {$[0.644,0.708]$} & {$[0.483,0.942]$} & {$[0.896,0.919]$} & {$[0.25,0.333]$} & {$[0.678,1]$} & {$[0.218,0.269]$} \\
\hline Shiraz & {$[0.505,0.554]$} & {$[0.577,1]$} & {$[0.804,0.873]$} & {$[1,1]$} & {$[0.528,0.821]$} & {$[0.269,0.291]$} \\
\hline Tabriz & {$[0.503,0.552]$} & {$[0.462,0.825]$} & {$[0.977,1]$} & {$[0.111,0.166]$} & {$[0.518,0.687]$} & {$[0.466,1]$} \\
\hline
\end{tabular}

Step 5.5.3. Construction of the weighted normalized matrix (Table 33).

Table 33

the weighted normalized decision matrix

\begin{tabular}{|c|c|c|c|c|c|c|}
\hline $\begin{array}{l}\text { The potential } \\
\text { Markets }\end{array}$ & $\begin{array}{c}\text { The } \\
\text { population }\end{array}$ & $\begin{array}{l}\text { the level of } \\
\text { income }\end{array}$ & the per capita & Local brands & $\begin{array}{l}\text { Distance from the } \\
\text { closest DC }\end{array}$ & Competitors \\
\hline Mashhad & {$[0.1410,0.156]$} & {$[0.0070,0.013]$} & {$[0.0029,0.00294]$} & {$[0.1086,0.3263]$} & {$[0.1500,0.1710]$} & {$[0.032,0.037]$} \\
\hline Isfahan & {$[0.1000,0.110]$} & {$[0.006,0.0120]$} & {$[0.00280,0.0029]$} & {$[0.0810,0.1080]$} & {$[0.0810,0.1080]$} & {$[0.035,0.043]$} \\
\hline Shiraz & {$[0.0800,0.086]$} & {$[0.007,0.0135]$} & {$[0.00250,0.0027]$} & {$[0.3263,0.3263]$} & {$[0.3263,0.3263]$} & {$[0.033,0.046]$} \\
\hline Tabriz & {$[0.078,0.0862]$} & {$[0.006,0.0110]$} & {$[0.00310,0.0032]$} & {$[0.036,0.05410]$} & {$[0.0360,0.0540]$} & {$[0.074,0.160]$} \\
\hline
\end{tabular}

Step 5.5.3*. as discussed in advance, to apply Tehran and West Azerbaijan as the ${ }^{1 \text { st }}$ rank and last rank (positive and negative ideal solutions) as the result of COPRAS-G method, (Eq.39-41) have been employed with the following steps.

Step 5.5.3**. Determining the positive ideal and negative-ideal alternatives as referential alternatives.

$S^{\max }=\{[0.903 .1] \cdot[0.577 .1] \cdot[0.977 .1] \cdot[1.1] \cdot[0.678 .1] \cdot[0.466 .1]\}$ 
$S^{\min }=\{[0.503 .0 .552] .[0.462 .0 .825] \cdot[0.804 .0 .873] \cdot[0.111 .0 .166] .[0.441 .0 .502] \cdot[0.2 .0 .233]\}$

Step 5.5.4. Computation of the weighted connection between each alternative sequence and the referential sequence in respect of (Eq.41). The ranking of the potential markets has been portrayed in (Table 34).

Table 34

ranking of the potential markets

\begin{tabular}{lccc}
\hline The potential Markets & $\Gamma_{i}$ & $1-\Gamma_{i}$ & Rank \\
\hline Mashhad & 0.2100071 & 0.789929 \\
Isfahan & 0.2190063 & 0.780993 & 3 \\
Shiraz & 0.1536851 & 0.846315 & 1 \\
Tabriz & 0.2394122 & 0.760587 & 4 \\
\hline
\end{tabular}

As exposed in the aforementioned table, the prioritization is Shiraz, Mashhad, Isfahan, and Tabriz respectively. Therefore, the target market is Shiraz.

\section{Discussion}

In order to investigate the optimal market selection of dairy companies, at the first step, the current markets have been defined in the six major indicators as the main criteria to prioritize the current markets in the next step. The following list: 1. The population; 2. The level of income; 3. The per capita consumption; 4. Local brands; 5. Distance from the closest DC; and 6. Competitors. In general, In MCDM problems, weight of each criterion extracts from the decision matrix with employing calculation algorithms such as Shannon's entropy, or DM decides the weights. In this paper, the Grey entropy has been utilized to calculate the weights of criteria.

After analyzing 107 participants' interview and 1100 questionnaires, as one of the results, we found that there is a direct connection between the tendency to local brands and the local culture, and also between the tendency to shop from the local brands and the number of local brands excluding Tehran. Thus, the number of local brands is used instead of the tendency to the local brands.

According to the aforesaid list of indicators, "competitors" is the last indicator which investigated. With respect to (Fig 5), to analyze this criterion, a hybrid model of MCDM methods employed. The analyzed competitors are as following list: Kalleh, Pegah, Damdaran, Sabbah, Choupan, Pajan, Ramak, Alis, Apadana. In line with the Grey TOPSIS algorithm, the ranking process results of the competitors against the four indicators of the product desirability, brand awareness, power of investment, and product availability are shown in (Table 13). To calculate the weight of each competitor, the "products cost" applied as the cost attribute with a negative effect on the prioritization process. The cost investigated in the three groups of products: cheese, yogurts and the beverages. After employing of SAW method to prioritize the competitors, the final results of ranking have been shown in (Table 15).

Dealing with the COPRAS-G method, prioritization process of the current market executed in the next step. In this step, we aimed to find the positive and negative ideal solution as the best and worst markets where the company sells its products. As detailed in (Table 1), the reasons of the COPRAS-G methodologies selection for the new approach are: It has noticeable advantages among the other methods, the calculation time is very short, and it can be implemented to any program source code as simple as VIKOR. Understanding and checking the results is very common and computation results can be easily visualized and interpreted. As the result (Theran $>$ The North $>$ Khuzestan $>$ West Azerbaijan), accordingly, Tehran and West Azerbaijan are the best and worst markets where the company sells its products, and play the role of the positive and negative ideal solutions in prioritization process of the potential markets by Grey TOPSIS technique.

In this paper, the fourth step of the proposed approach is "the definition of the potential markets that the company intends to sell its products". Resembling the current markets, the potential markets have been defined in the six indicators as well.

The last step of the new approach is dedicated to the selection of markets. In order to select the best potential markets, the approach deal with the Grey TOPSIS. In the original algorithm of the Grey TOPSIS, unlike the TOPSIS algorithm, the best alternative is determined based on the positive ideal solution. Therefore, to find a solution for the mentioned problem, the approach used the improved algorithm of the Grey TOPSIS with positive and negative ideal solutions developed by (Jadidi et al., 2009). According to the current markets ranking result, Tehran has been selected as the positive ideal solution and the best market where the company sells its products, and West Azerbaijan has been designated as the worst market while it has the minimum standards of company's products selling. Thus, with these two markets, the interval has been made which has the maximum and minimum standards of the company's products selling. The aforementioned numeric interval is the main advantage that the proposed methodology offers for the selection of the best market for dairy companies. In the proposed methodology, the weights of criteria in prioritization of the potential markets are as same as the weights of the criteria in the prioritization of the currents markets, due to that we assumed that the quantity of the weights of criteria in the prioritization of the potential markets has the same impact as the weights of criteria in the prioritization process of the currents markets. According to Grey Entropy, the weights of criteria extracted from the decision matrix of the potential markets is demonstrated in (Table 35):

Table 35

Entropy and the weight of each criterion

\begin{tabular}{|c|c|c|c|c|c|c|c|c|c|c|}
\hline & The population & & $\begin{array}{l}\text { el of } \\
\text { ne }\end{array}$ & $\begin{array}{l}\text { the } p \\
\text { cons }\end{array}$ & & Loca & inds & $\begin{array}{l}\text { Dista } \\
\text { the cl }\end{array}$ & $\begin{array}{l}\text { from } \\
\text { st DC }\end{array}$ & Competitors \\
\hline$e_{j}$ & 0.8351 & 0.9888 & 0.8041 & 0.2771 & 0.490 & 0.3098 & 0.5280 & 0.9395 & 0.5524 & 0.9832 \\
\hline
\end{tabular}




\begin{tabular}{|c|c|c|c|c|c|c|c|c|c|c|c|c|}
\hline$d_{j}$ & 0.2309 & 0.1684 & 0.0111 & 0.8104 & 0.7228 & 0.5092 & 0.3098 & 0.5208 & 0.0604 & 0.3370 & 0.0168 & 0.2412 \\
\hline$w_{j}$ & 0.171 & 0.064 & 0.0082 & 0.3004 & 0.5347 & 0.1888 & 0.2291 & 0.1930 & 0.046 & 0.166 & 0.0124 & 0.0894 \\
\hline$W_{j}$ & \multicolumn{2}{|c|}{0.1167} & \multicolumn{2}{|c|}{0.1543} & \multicolumn{2}{|c|}{0.35617} & \multicolumn{2}{|c|}{0.21105} & \multicolumn{2}{|c|}{0.1053} & \multicolumn{2}{|c|}{0.0509} \\
\hline
\end{tabular}

The comparison between entropies of each criterion in the two prioritizations algorithms of the current and the potential markets is illustrated in (Fig.7). In (Fig.7) and (Fig.8), the comparisons have been presented as a numerical interval.

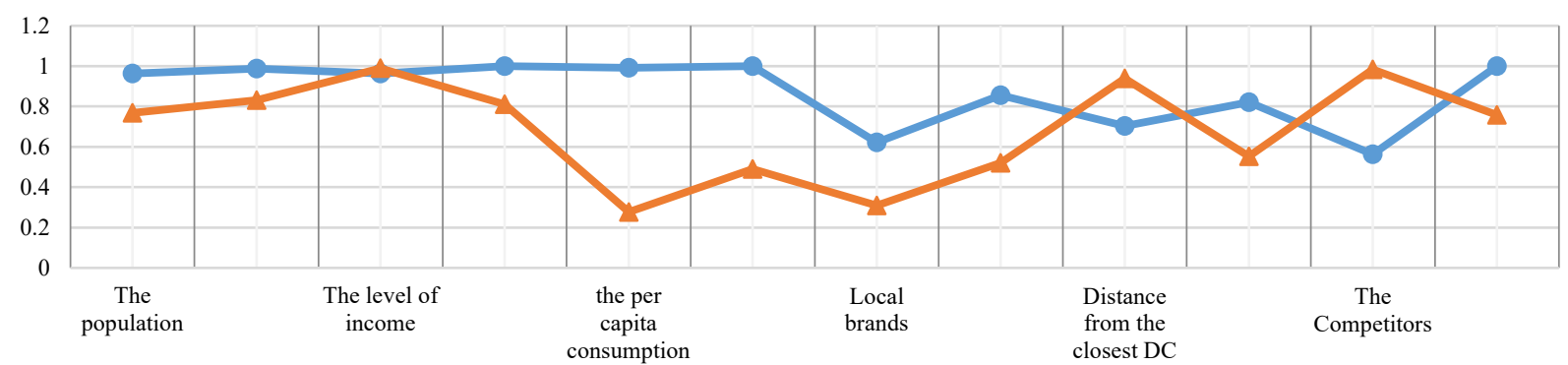

Fig.7.The comparison between entropy of each criterion in the current and the potential markets selection decision matrix. The orange line shows the entropy in potential markets decision matrix and the blue exposes the entropy in current markets decision matrix.

The comparison analysis of raw weights of each criterion in the prioritization of the potential markets with the raw weights of each criterion in the prioritization algorithm of the current markets is portrayed in (Fig.8):

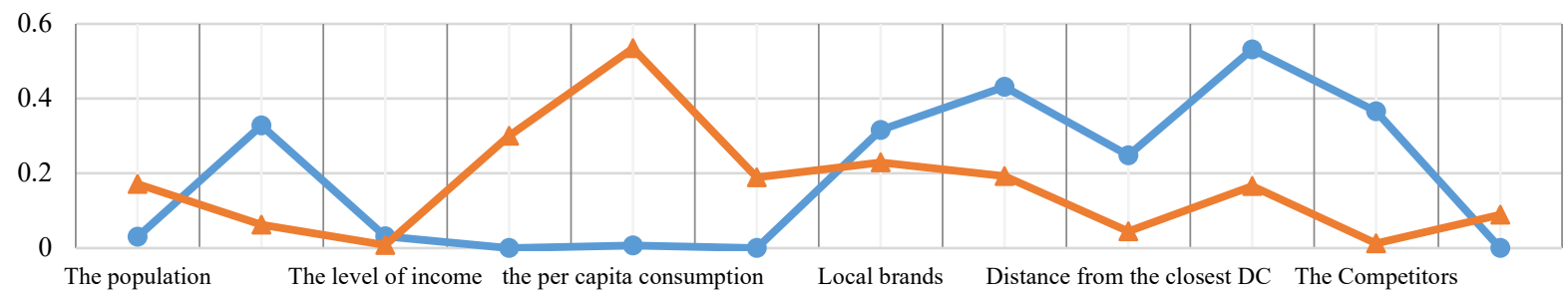

Fig.8. the comparison between the raw weights

As presented in (Fig 8), The orange line depicts the raw weights of each criterion in the current market prioritization process, and the blue line represents the raw weights of each criterion in algorithm of current market selection. And the final comparison is conducted between the weights of each criterion in the two decision matrices of the current and the potential markets. The difference between the two final weights of each criterion has been shown in (Fig 9), where The orange line is for potential and the blue line is for the current markets decision matrices. As mentioned in advance, the final weights are the crisp numbers.

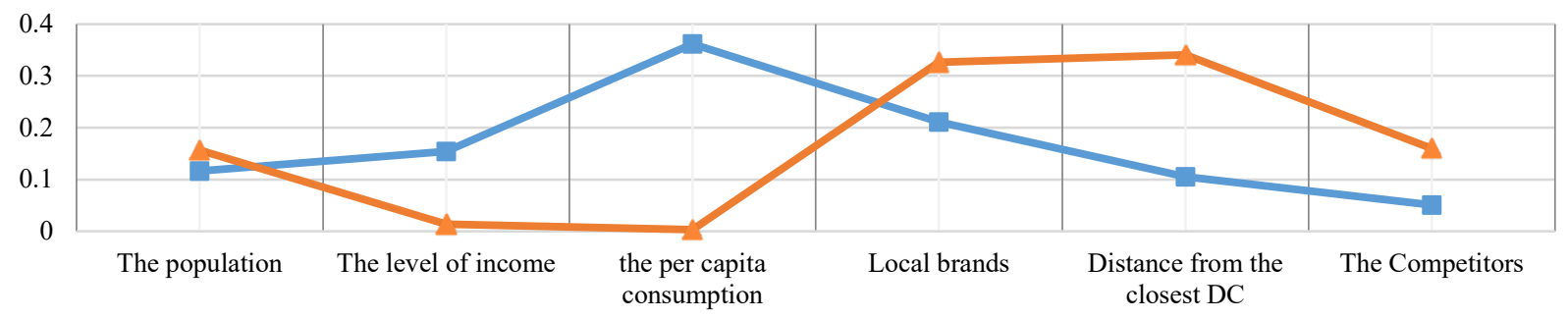

Fig.9.The comparison analysis of the final weights of each criterion in potential and current markets decision matrices

Without consideration of Tehran and West Azerbaijan as the positive and negative ideal solutions in TOPSIS algorithm, the ranking of potential markets is stated in (Table 36):

Table 36

the ranking of potential markets without consideration of positive and negative ideal solutions of current markets ranking

\begin{tabular}{lccc}
\hline The potential Markets & $C_{i}$ & $1-C_{i}$ & Rank \\
\hline Mashhad & 0.38066 & 0.61934 & 1 \\
Isfahan & 0.40916 & 0.59084 & 2 \\
Shiraz & 0.57885 & 0.42115 & 4 \\
Tabriz & 0.57250 & 0.42750 & 3 \\
\hline
\end{tabular}

The comparison between $\left(1-C_{i}\right)$ and $\left(1-\Gamma_{i}\right)$ shows the difference between ranking of the two algorithms, which has been illustrated in (Fig 10). 


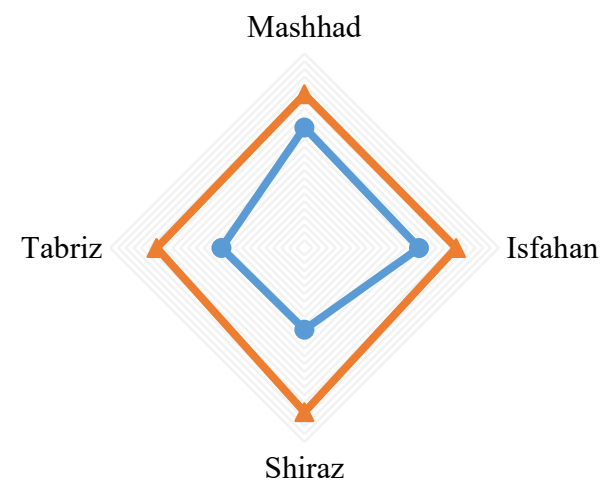

Fig.10.The differences between rankings. The blue line is the $\left(1-C_{i}\right)$ and the orange line is the $\left(1-\Gamma_{i}\right)$.

As it can be seen, without consideration of Tehran and West Azerbaijan as the positive and negative ideal solutions, the ranking is as (Mashhad > Isfahan > Shiraz > Tabriz), while the new approach offers following ranking of the potential markets, where Shiraz has been selected as the best potential market: (Shiraz $>$ Mashhad $>$ Isfahan $>$ Tabriz).

\section{Managerial implications}

Our results seem to suggest that the current markets can be used as the tools to elicit the target market. Due to the new approach's numerical logic, it also can be used in the international dairy markets. Likewise, the new approach has the potential to be expanded in many different markets and industries as well. The core of the new approach is constructed around the company's current situation, abilities and resources to select the best target market where the company can optimally meet the market's needs. In actual fact, the new approach reflects the reality of the markets, not an abstract images of the markets which mislead managers in their decision-making. The presented approach provides an integrated analysis tool based on the two different approaches, where one of them is embodied in the evaluation of the current markets, while the other one analyzes the targets markets independently. The selected target market through the new approach is authenticated not only as the company's best current market, but it is the best near future market and also a launch pad for the company's market development strategy.

\section{Conclusion}

As a new approach for the market selection for dairy companies, this paper attempts to present a formulated framework to select the target markets (the potential markets) in line with the current markets. The new approach provides the competence that the selected market overlays not only the company's limitations to feed the market needs but also embraces the current markets' advantages which is the main objective of this research. To achieve the objective, we developed the TOPSIS method by integration of G-TOPSIS and COPRAS-G.

In conclusion, we are currently extending this model to use as the strategic tool to select the potential target markets in Doosheh Dairy Co and preliminary results are encouraging. The sources of this paper are the data which achieved by Marketing Research Department of Doosheh Dairy Co. We believe our work provides valuable database towards other researches in Iranian dairy market. The dairy market environment is extremely dynamic with the highly oscillation in the market indices, thus the dairy potential market selection is a complex problem. Especially in Iran, there are many criteria which impact on the selection of markets. Despite the fact that the important criteria in dairy market selection in this research have been investigated in terms of time, market or firm's conditions, there are other criteria that would impact on the target market selection. Suggestion for future works are as follows: Further practices can be on investigation of hybrid models of sales, DC construction cost and chain stores effect on the potential dairy market selection in Iran. The growing rate of chain stores establishment affirms the consumer orientation to do the shopping from chain stores. Firms must consider the impact of chain stores on their potential market selection. In MENA region, political issues such as upcoming sanctions greatly effect on business plans and strategies. Currently, after Iranian nuclear deal, domestic market gates have been opened to connect with other countries. It has two different aspects of threats and opportunities. On one hand, there are threats of imports from strong economies with attractive competitive advantages or entrance of strong multinational companies to the current market and on the other hand, the opportunities of exports to other countries. The consumer's tendency and markets orientation to imported products are two other criteria which must be investigated in potential market selection of dairy firms. 


\section{Acknowledgement}

This research was supported by Doosheh Dairy Company. We thank our colleagues from Marketing Research Department of Doosheh Dairy Co who provided insight, expertise and data that greatly assisted the research.

We would also like to sincerely thank Doosheh Dairy Company's CEO, Mr. Bozorgmehr Dadgar for assistance with his financial and spiritual support and our colleagues from Sales Planning Department of Doosheh Dairy Co for comments that greatly improved the manuscript.

\section{Appendix}

The prioritization and selection of the potential markets without consideration of the current markets ranking is in accordance with the following steps:

Step 1.Construction of the decision matrix.

Table

decision matrix of the potential markets prioritization

\begin{tabular}{|c|c|c|c|c|c|c|}
\hline $\begin{array}{l}\text { The potential } \\
\text { Markets }\end{array}$ & $\begin{array}{c}+ \\
\text { The population }\end{array}$ & $\begin{array}{l}+ \\
\text { the level of income }\end{array}$ & $\begin{array}{c}+ \\
\text { the per capita }\end{array}$ & $\begin{array}{c}\text { - } \\
\text { Local } \\
\text { brands }\end{array}$ & $\begin{array}{l}- \\
\text { Distance from the } \\
\text { closest DC }\end{array}$ & Competitors \\
\hline Mashhad & {$[2772287,3069941]$} & {$[97429063,183912000]$} & {$[79,80]$} & {$[1,3]$} & {$[717.4,815.8]$} & {$[3.33334,3.88889]$} \\
\hline Isfahan & {$[1978168,2174172]$} & {$[93390015,182231000]$} & {$[78,80]$} & {$[3,4]$} & {$[360,530.5]$} & {$[2.88889,3.55557]$} \\
\hline Shiraz & {$[1549453,1700687]$} & {$[111740495,193411000]$} & {$[70,76]$} & {$[0,1]$} & {$[438.4,681.4]$} & {$[2.66667,2.8889]$} \\
\hline Tabriz & {$[1545491,1695094]$} & {$[89345632,159690000]$} & {$[85,87]$} & {$[6,9]$} & {$[523.7,694.8]$} & {$[0.77778,1.66667]$} \\
\hline
\end{tabular}

Step 2.Construction of the Normalized decision matrix.

Table

the normalized decision matrix

\begin{tabular}{|c|c|c|c|c|c|c|}
\hline \multirow[t]{2}{*}{$W_{j}$} & 0.1563 & 0.0135 & 0.0032 & 0.3263 & 0.3408 & 0.16 \\
\hline & + & + & + & - & - & - \\
\hline $\begin{array}{l}\text { The potential } \\
\text { Markets }\end{array}$ & The population & the level of income & the per capita & $\begin{array}{l}\text { Local } \\
\text { brands }\end{array}$ & $\begin{array}{l}\text { Distance from } \\
\text { the closest DC }\end{array}$ & Competitors \\
\hline Mashhad & {$[0.903,1]$} & {$[0.504,0.951]$} & {$[0.908,0.919]$} & {$[0.333,1]$} & {$[0.441,0.502]$} & {$[0.2,0.233]$} \\
\hline Isfahan & {$[0.644,0.708]$} & {$[0.483,0.942]$} & {$[0.896,0.919]$} & {$[0.25,0.333]$} & {$[0.678,1]$} & {$[0.218,0.269]$} \\
\hline Shiraz & {$[0.505,0.554]$} & {$[0.577,1]$} & {$[0.804,0.873]$} & {$[1,1]$} & {$[0.528,0.821]$} & {$[0.269,0.291]$} \\
\hline Tabriz & {$[0.503,0.552]$} & {$[0.462,0.825]$} & {$[0.977,1]$} & {$[0.111,0.166]$} & {$[0.518,0.687]$} & {$[0.466,1]$} \\
\hline
\end{tabular}

Step 3. Utilization of the grey entropy to calculate the weights of criteria.

Table

Entropy and the raw weight of each criteria

\begin{tabular}{|c|c|c|c|c|c|c|c|c|c|c|c|c|}
\hline \multirow{2}{*}{$\begin{array}{l}\text { The Current } \\
\text { Markets } \\
e_{j}\end{array}$} & \multicolumn{2}{|c|}{ The population } & \multicolumn{2}{|c|}{$\begin{array}{l}\text { the level of } \\
\text { income }\end{array}$} & \multicolumn{2}{|c|}{$\begin{array}{l}\text { the per capita } \\
\text { consumption }\end{array}$} & \multicolumn{2}{|c|}{ Local brands } & \multicolumn{2}{|c|}{$\begin{array}{l}\text { Distance from } \\
\text { the closest DC }\end{array}$} & \multicolumn{2}{|c|}{ Competitors } \\
\hline & 0.7691 & 0.8351 & 0.988 & 0.8104 & 0.2771 & 0.4907 & 0.3098 & 0.520 & 0.9395 & 0.5524 & 0.9832 & 0.7587 \\
\hline$d_{j}$ & 0.2309 & 0.1684 & 0.011 & 0.8104 & 0.7228 & 0.5092 & 0.3098 & 0.520 & 0.0604 & 0.4476 & 0.0168 & 0.2412 \\
\hline$w_{j}$ & 0.171 & 0.0624 & 0.082 & 0.304 & 0.5347 & 0.1888 & 0.2291 & 0.193 & 0.0446 & 0.166 & 0.0124 & 0.0894 \\
\hline$W_{j}$ & \multicolumn{2}{|c|}{0.1167} & \multicolumn{2}{|c|}{0.1543} & \multicolumn{2}{|c|}{0.36175} & \multicolumn{2}{|c|}{0.21105} & \multicolumn{2}{|c|}{0.1053} & \multicolumn{2}{|c|}{0.0509} \\
\hline
\end{tabular}

Step 4. Establishment of the weighted normalized decision matrix.

Table

weighted normalized matrix

\begin{tabular}{lcccccc}
\hline $\begin{array}{l}\text { The potential } \\
\text { Markets }\end{array}$ & The population & $\begin{array}{c}\text { the level of } \\
\text { income }\end{array}$ & the per capita & Local brands & $\begin{array}{c}\text { Distance from } \\
\text { the closest DC }\end{array}$ & $\begin{array}{c}\text { Competitors } \\
\text { Mashhad }\end{array}$ \\
Isfahan & {$[0.1053,0.1167]$} & {$[0.0777,0.1467]$} & {$[0.3284,0.3324]$} & {$[0.0703,0.21105]$} & {$[0.0464,0.053]$} & {$[0.0102,0.012]$} \\
Shiraz & {$[0.0751,0.0826]$} & {$[0.0745,0.1453]$} & {$[0.3241,0.3324]$} & {$[0.0527,0.0703]$} & {$[0.0717,0.1053]$} & {$[0.0111,0.0137]$} \\
Tabriz & {$[0.0587,0.0644]$} & {$[0.0713,0.1272]$} & {$[0.3534,0.3617]$} & {$[0.0234,0.035]$} & {$[0.0555,0.0864]$} & {$[0.0137,0.015]$} \\
\hline
\end{tabular}

Step 5.Calculation of $\left(S^{\max }\right)$ as the ideal alternative where $\left(S^{\max }\right)$ is as the following content:

$S^{\max }=\{[0.1053 .0 .1167]$. [0.089.0.1543]. [0.3534.0.3617]. [0.21105.0.21105]. [0.0717.0.1053]. [0.024.0.0509]\}

Step 6. Computation of the distance between each of the alternatives sequences:

$$
\left[\begin{array}{cccccc}
0 & 0.0189 & 0.0543 & 0.14075 & 0.0776 & 0.0527 \\
0.0643 & 0.0235 & 0.0586 & 0.2991 & 0 & 0.0501 \\
0.0985 & 0 & 0.1081 & 0 & 0.0351 & 0.0462 \\
0.0989 & 0.0448 & 0 & 0.3637 & 0.0502 & 0
\end{array}\right]
$$

Step. 7. Determination of the grey relation coefficient between each of the alternatives:

Table

the procedure of $\min _{i} \min _{j} \Delta_{i}(j)$ and $\max _{i} \max _{j} \Delta_{i}(j)$ computation 


\begin{tabular}{c|cccccccc}
\hline & $\mathrm{C}_{1}$ & $\mathrm{C}_{2}$ & $\mathrm{C}_{3}$ & $\mathrm{C}_{4}$ & $\mathrm{C}_{5}$ & $\mathrm{C}_{6}$ & $\min _{j} \Delta_{i}(j)$ & $\max _{j} \Delta_{i}(j)$ \\
\hline$\Delta_{1}(j)$ & 0 & 0.0189 & 0.0543 & 0.14075 & 0.0776 & 0.0527 & 0 & 0.14057 \\
$\Delta_{2}(j)$ & 0.0643 & 0.0235 & 0.0586 & 0.2991 & 0 & 0.0501 & 0 & 0.2991 \\
$\Delta_{3}(j)$ & 0.0985 & 0 & 0.1081 & 0 & 0.0351 & 0.0462 & 0 & 0.1081 \\
$\Delta_{4}(j)$ & 0.0989 & 0.0448 & 0 & 0.3637 & 0.0502 & 0 & 0 & 0.3637 \\
$\min _{i} \min _{j} \Delta_{i}(j)$ & & & & & & & & 0 \\
$\max _{i} \max _{j} \Delta_{i}(j)$ & & & & & & & & 0.3637 \\
\hline
\end{tabular}

Table

Grey relation coefficient between each of the alternatives

\begin{tabular}{cccccc}
\hline \multicolumn{7}{c}{$\gamma_{o i}$} & & & \\
\hline $\mathrm{C}_{1}$ & $\mathrm{C}_{2}$ & $\mathrm{C}_{3}$ & $\mathrm{C}_{4}$ & $\mathrm{C}_{6}$ & 0.775 \\
0.906 & 0.77 & 0.564 & 0.701 & 0 & 0.784 \\
0.74 & 0.885 & 0.756 & 0.38 & 0.84 & 0.4099 \\
0.65 & 0 & 0.627 & 0 & 0.783 & 0 \\
0.647 & 0.802 & 0 & 0.333 &
\end{tabular}

Step 8. Computing the grade of grey relation of each alternative to the ideal solution.

Table

ranking of potential markets

\begin{tabular}{|c|c|c|}
\hline & $C_{i}$ & Rank \\
\hline Mashhad & 0.38066 & 1 \\
\hline Isfahan & 0.40916 & 2 \\
\hline Shiraz & 0.57885 & 4 \\
\hline Tabriz & 0.5725 & 3 \\
\hline
\end{tabular}

\section{References}

1. Agbo, M., Rousselière, D., \& Salanié, J. (2015). Agricultural marketing cooperatives with direct selling: A cooperative-non-cooperative game. Journal of Economic Behavior \& Organization, 109, 56-71. https://doi.org/10.1016/j.jebo.2014.11.003

2. Aghdaie, M. H., \& Alimardani, M. (2015). Target market selection based on market segment evaluation: a multiple attribute decision making approach. International Journal of Operational Research, 24(3), 262-278. 10.1504/IJOR.2015.072231

3. Aghdaie, M. H., Zolfani, S. H., \& Zavadskas, E. K. (2013). Market segment evaluation and selection based on application of fuzzy AHP and COPRAS-G methods. Journal of Business Economics and Management, 14(1), 213-233. https://doi.org/10.3846/16111699.2012.721392

4. Aghdaie, M. H., Zolfani, S. H., Rezaeinia, N., \& Mehri-Tekmeh, J. (2011). A hybrid fuzzy MCDM approach for market segments evaluation and selection. In Management and Service Science (MASS), 2011 International Conference on (pp. 1-4). IEEE.

5. Aksoy S., Ozbuk M., Multiple criteria decision making in hotel location: Does it relate to postpurchase consumer evaluations?, Tourism Management Perspectives, Volume 22, April 2017, Pages 73-81.

6. Antoniou, F., \& Aretoulis, G. N. (2018). Comparative analysis of multi-criteria decision making methods in choosing contract type for highway construction in Greece. International Journal of Management and Decision Making, 17(1), 1-28. https://doi.org/ 10.1504/IJMDM.2018.088813

7. Barney, J. P., \& Smith, T. R. (1998). How local dairy communities can compete in the global marketplace. Journal of dairy science, 81(6), 1762-1768. https://doi.org/10.3168/jds.S0022-0302(98)75745-5

8. Bazhan, M., Kalantari, N., Keshavarz-Mohammadi, N., Hosseini, H., Eini-Zinab, H., \& Alavi-Majd, H. (2018). Applying social marketing mix to identify consumers' preferences towards functional dairy products in Iran. Nutrition \& Food Science, 48(1), 45-60. https://doi.org/10.1108/NFS-04-2017-0067

9. Bazhan, M., Keshavarz-Mohammadi, N., Hosseini, H., \& Kalantari, N. (2017). Consumers' awareness and perceptions regarding functional dairy products in Iran: a qualitative research. British Food Journal, 119(2), 253-266. https://doi.org/10.1108/BFJ-06-20160270

10. Bolotova, Y. V. (2016). Agricultural supply management and market power: Evidence from the US dairy and potato industries. Agribusiness, 32(4), 563-568. https://doi.org/10.1002/agr.21485

11. Bouzon M., Govindan K., Rodriguez, M., Evaluating barriers for reverse logistics implementation under a multiple stakeholders' perspective analysis using grey decision making approach, Resources, Conservation and Recycling, 2017, In Press.

12. Briley, D., Wyer Jr, R. S., \& Li, E. (2014). A dynamic view of cultural influence: A review. Journal of Consumer Psychology, 24(4), 557-571. https://doi.org/10.1016/j.jcps.2014.02.003

13. Burlakoti, M., \& Rajbhandari, B. P. (2016). Sustainable agriculture: marketing opportunities for the products grown with IPM in Terai districts. Nepalese Journal of Agricultural Sciences, 14, 175-182. http://www.hicast.edu.np/uploads/colleges/16/582eab6d9e293.pdf

14. Cakir, M., \& Balagtas, J. V. (2010). Econometric evidence of cross-market effects of generic dairy advertising. Agribusiness, 26(1), 8399.

15. Certa, A., Enea, M., Galante, G. M., Izquierdo, J., \& Fata, C. M. L. (2018). Food safety risk analysis from the producers' perspective: prioritisation of production process stages by HACCP and TOPSIS. International Journal of Management and Decision Making, 17(4), 396-414. https://doi.irg/10.1504/IJMDM.2018.095720

16. Chatterjee, P., Athawale, V. M., \& Chakraborty, S. (2011). Materials selection using complex proportional assessment and evaluation of mixed data methods. Materials \& Design, 32(2), 851-860. https://doi.org/10.1016/j.matdes.2010.07.010 
17. Chatterjee, P., Athawale, V. M., \& Chakraborty, S. (2011). Materials selection using complex proportional assessment and evaluation of mixed data methods. Materials \& Design, 32(2), 851-860. https://doi.org/10.1016/j.matdes.2010.07.010

18. Das Adhikary, D., Kumar Bose, G., Bose, D., \& Mitra, S. (2014). Multi criteria FMECA for coal-fired thermal power plants using COPRAS-G. International Journal of Quality \& Reliability Management, 31(5), 601-614. https://doi.org/10.1108/IJQRM-04-20130068

19. Das, M. C., Sarkar, B., \& Ray, S. (2012). A framework to measure relative performance of Indian technical institutions using integrated fuzzy AHP and COPRAS methodology. Socio-Economic Planning Sciences, 46(3), 230-241. https://doi.org/10.1016/j.seps.2011.12.001

20. Deng, J. L. (1985). Fundamental methods of grey systems. Huazhoug University of Science and Technology, Wuhan, China.

21. Deng, J. L. (1989). Introduction to grey system theory. The Journal of grey system, 1(1), 1-24.

22. Deng, J. L. (1990). A course on grey system theory. Huazhong University of Science and Technology Press, Wuhan.

23. Dolnicar, S., Grün, B., \& Leisch, F. (2018). Market Segmentation Analysis. In Market Segmentation Analysis (pp. 11-22). Springer, Singapore. https://doi.org/10.1007/978-981-10-8818-6_2

24. Dymova, L., Sevastjanov, P., \& Tikhonenko, A. (2013). An approach to generalization of fuzzy TOPSIS method. Information Sciences, 238, 149-162. https://doi.org/10.1016/j.ins.2013.02.049

25. Efe B., An integrated fuzzy multi criteria group decision making approach for ERP system selection, Applied Soft Computing, Volume 38, January 2016, Pages 106-117.

26. FOZOUNI, A. Z., Farhadian, H., \& PEZESHKIRAD, G. R. (2017). Determine the Degree of Dairy Industry Development in Iran Provinces; Using Numerical Taxonomy Technique. https://www.sid.ir/En/Journal/ViewPaper.aspx?ID=507768

27. Golijan, J., \& Popović, A. (2016, November). Basic characteristics of the organic agriculture market. In Fifth International Conference "Competitiveness of agro-food and environmental economy (pp. 10-11). http://www.cafee.ase.ro/wpcontent/upload/2016edition/file2016(27).pdf

28. Grau, A., \& Hockmann, H. (2018). Market power in the German dairy value chain. Agribusiness, 34(1), 93-111. https://doi.org/10.1002/agr.21529

29. Hansen, B. G., \& Li, Y. (2017). An analysis of past world market prices of feed and milk and predictions for the future. Agribusiness, 33(2), 175-193. https://doi.org/10.1002/agr.21474

30. Hwang, C.L. and Yoon, K. (1981), Multiple Attribute Decision Making Methods and Applications, Springer, Berlin, Heidelberg. https://doi.org/10.1007/978-3-642-48318-93

31. Imam, A., Zadeh, M. N., \& Dubey, L. R. (2011). Dairy marketing strategies in the context of globalization: Issues and Challenges. International Journal of Trade, Economics and Finance, 2(2), 138.

32. Jadidi, O., Sai Hong, T., Firouzi, F., \& Yusuff, R. M. (2009). An optimal grey based approach based on TOPSIS concepts for supplier selection problem. International Journal of Management Science and Engineering Management, 4(2), $104-117$. https://doi.org/10.1080/17509653.2009.10671066

33. Jia, X., Luan, H., Huang, J., Li, S., \& Rozelle, S. (2014). Marketing raw milk from dairy farmers before and after the 2008 milk scandal in China: evidence from greater Beijing. Agribusiness, 30(4), 410-423. https://doi.org/10.1002/agr.21375

34. Kaklauskas, A., Zavadskas, E. K., \& Raslanas, S. (2005). Multivariant design and multiple criteria analysis of building refurbishments. Energy and Buildings, 37(4), 361-372. https://doi.org/10.1016/j.enbuild.2004.07.005

35. Kaklauskas, A., Zavadskas, E. K., Raslanas, S., Ginevicius, R., Komka, A., \& Malinauskas, P. (2006). Selection of low-e windows in retrofit of public buildings by applying multiple criteria method COPRAS: A Lithuanian case.Energy and Buildings, 38(5), 454-462. https://doi.org/10.1016/j.enbuild.2005.08.005

36. Karthikeyan, G. (2016). Problems in the marketing of agricultural goods. International Journal of Multidisciplinary Research and Modern Education (IJMRME), 233-235. http://rdmodernresearch.org/wp-content/uploads/2016/03/165.pdf

37. Khodaverdi, R., \& Hashemi, S. H. (2015). A grey-based decision-making approach for selecting a reverse logistics provider in a closed loop supply chain. International Journal of Management and Decision Making, 14(1), 32-43. https://doi.org/10.1504/IJMDM.2015.067376

38. Kwon, M., Saluja, G., \& Adaval, R. (2015). Who said what: The effects of cultural mindsets on perceptions of endorser-message relatedness. Journal of Consumer Psychology, 25(3), 389-403. https://doi.org/10.1016/j.jcps.2015.01.011

39. Lalwani, A. K., \& Shavitt, S. (2013). You get what you pay for? Self-construal influences price-quality judgments. Journal of Consumer Research, 40(2), 255-267. https://doi.org/10.1086/670034

40. Lin, Y., Chen, M. Y., \& Liu, S. (2004). Theory of grey systems: capturing uncertainties of grey information. Kybernetes, 33(2), 196218. https://doi.org/10.1108/03684920410514139

41. Liu, J., Liao, X., Huang, W., \& Liao, X. (2019). Market segmentation: A multiple criteria approach combining preference analysis and segmentation decision. Omega, 83, 1-13. https://doi.org/10.1016/j.omega.2018.01.008

42. Marchant, M. A., \& Neff, S. A. (1995). Interaction of United States and European Community Dairy Policies Through the International Market2. Journal of dairy science, 78(5), 1191-1198. https://doi.org/10.3168/jds.S0022-0302(95)76737-6

43. McDONALD, M., \& DUNBAR, I. (2004). Market segmentation: how todo it, how to profit from it. Burlington, UK: Elsevier Butterworth-Heinemann

44. Mulliner, E., Malys, N., \& Maliene, V. (2016). Comparative analysis of MCDM methods for the assessment of sustainable housing affordability.Omega, 59, 146-156. https://doi.org/10.1016/j.omega.2015.05.013

45. National Commission on Agriculture. (1976). Report of the National Commission on Agriculture. Ministry of Agriculture and Irrigation.

46. Nuuter, T., Lill, I., \& Tupenaite, L. (2015). Comparison of housing market sustainability in European countries based on multiple criteria assessment. Land Use Policy, 42, 642-651. https://doi.org/10.1016/j.landusepol.2014.09.022

47. Nuuter, T., Lill, I., \& Tupenaite, L. (2015). Comparison of housing market sustainability in European countries based on multiple criteria assessment. Land Use Policy, 42, 642-651. https://doi.org/10.1016/j.landusepol.2014.09.022

48. Ou C. W., Chouand S., Chang Y. H., Using a strategy-aligned fuzzy competitive analysis approach for market segment evaluation and selection," Expert Systems with Applications, vol. 36no. 1, pp. 527- 541, 2009. 
49. Peng, Y., Kou, G., Wang, G., Wang, H., \& Ko, F. I. (2009). Empirical evaluation of classifiers for software risk management. International Journal of Information Technology \& Decision Making, 8(04), $749-767$. https://doi.org//10.1142/S0219622009003715

50. Peng, Y., Wang, G., \& Wang, H. (2012). User preferences based software defect detection algorithms selection using MCDM. Information Sciences, 191, 3-13. https://doi.org/10.1016/j.ins.2010.04.019

51. Pinior, B., Konschake, M., Platz, U., Thiele, H. D., Petersen, B., Conraths, F. J., \& Selhorst, T. (2012). The trade network in the dairy industry and its implication for the spread of contamination. Journal of dairy science, 95(11), 6351-6361. https://doi.org/10.3168/jds.2012-5809

52. Rahnama, H., \& Rajabpour, S. (2017). Factors for consumer choice of dairy products in Iran. Appetite, 111, 46-55. https://doi.org/10.1016/j.appet.2016.12.004

53. Riemer, H., Shavitt, S., Koo, M., \& Markus, H. R. (2014). Preferences don't have to be personal: Expanding attitude theorizing with a cross-cultural perspective. Psychological review, 121(4), 619. http://psycnet.apa.org/journals/rev/121/4/619/

54. Rokach, L. (2010). Ensemble-based classifiers. Artificial Intelligence Review,33(1-2), 1-39. https://doi.org/10.1007/s10462-009-91247

55. Sahu, S. K., Datta, S., \& Mahapatra, S. S. (2015). Appraisement and benchmarking of supply chain performance extent: A fuzzy grey relation method. Grey Systems: Theory and Application, 5(1), 2-30. https://doi.org/10.1108/GS-10-2014-0036

56. Sarti, S., Darnall, N., \& Testa, F. (2018). Market segmentation of consumers based on their actual sustainability and health-related purchases. Journal of Cleaner Production, 192, 270-280. https://doi.org/10.1016/j.jclepro.2018.04.188

57. Schmidt, M. C., Kolodinsky, J. M., DeSisto, T. P., \& Conte, F. C. (2016). Increasing farm income and local food access: A case study of a collaborative aggregation, marketing, and distribution strategy that links farmers to markets. Journal of Agriculture, Food Systems, and Community Development, 1(4), 157-175.

58. Shannon, C. E. (2001). A mathematical theory of communication. ACM SIGMOBILE Mobile Computing and Communications Review, 5(1), 3-55. http://dl.acm.org/citation.cfm?id=584093

59. Shavitt, S., \& Cho, H. (2016). Culture and consumer behavior: the role of horizontal and vertical cultural factors. Current opinion in psychology, 8, 149-154. https://doi.org/10.1016/j.copsyc.2015.11.007

60. Shavitt, S., \& Cho, H. (2016). Culture and consumer behavior: the role of horizontal and vertical cultural factors. Current opinion in psychology, 8, 149-154. https://doi.org/10.1016/j.copsyc.2015.11.007

61. Shavitt, S., Jiang, D., \& Cho, H. (2016). Stratification and segmentation: Social class in consumer behavior. Journal of Consumer Psychology, 26(4), 583-593. https://doi.org/10.1016/j.jcps.2016.08.005

62. Stanujkic, D., Djordjevic, B., \& Djordjevic, M. (2013). Comparative analysis of some prominent MCDM methods: A case of ranking Serbian banks.Serbian Journal of Management, 8(2), 213-241. https://doi.org/10.5937/sjm8-3774

63. Stukenberg, D., Blayney, D., \& Miller, J. (2006). Major advances in milk marketing: Government and industry consolidation. Journal of dairy science, 89(4), 1195-1206. https://doi.org/10.3168/jds.S0022-0302(06)72189-0

64. Thakur, V., Ramesh, A., Selection of Waste Disposal Firms Using Grey Theory Based Multi-criteria Decision Making Technique, Procedia - Social and Behavioral Sciences, Volume 189, 15 May 2015, Pages 81-90.

65. Thomsen, F. L. (1951). Agricultural marketing. McGraw-Hill Book Company, Inc.; New York.

66. Tian, Z. P., Wang, J. Q., \& Zhang, H. Y. (2018). Hybrid single-valued neutrosophic MCGDM with QFD for market segment evaluation and selection. Journal of Intelligent \& Fuzzy Systems, 34(1), 177-187. https://doi.org/10.3233/JIFS-171055

67. Torelli, C. J., Özsomer, A., Carvalho, S. W., Keh, H. T., \& Maehle, N. (2012). Brand concepts as representations of human values: do cultural congruity and compatibility between values matter?. Journal of Marketing, 76(4), 92-108. https://doi.org/10.1509/jm.10.0400

68. Wang, P., Zhu, Z., \& Wang, Y. (2016). A novel hybrid MCDM model combining the SAW, TOPSIS and GRA methods based on experimental design. Information Sciences. https://doi.org/10.1016/j.ins.2016.01.076

69. Wu, C., Buyya, R., \& Ramamohanarao, K. (2018). Cloud computing market segmentation. ICSOFT Proceeding, 888-897. http://DOI.org/10.5220/0006928008880897

70. Wu, D. (2006). Fuzzy group decision making based on grey relative analysis. International Journal of Management and Decision Making, 7(4), 454-472. https://doi.org/10.1504/IJMDM.2015.067376

71. Xiao, Z., Xia, S., Gong, K., \& Li, D. (2012). The trapezoidal fuzzy soft set and its application in MCDM. Applied Mathematical Modelling, 36(12), 5844-5855. https://doi.org/10.1016/j.apm.2012.01.036

72. Yang, H., Stamatogiannakis, A., \& Chattopadhyay, A. (2015). Pursuing attainment versus maintenance goals: The interplay of selfconstrual and goal type on consumer motivation. Journal of Consumer Research, 42(1), 93-108. https://doi.org/10.1093/jcr/ucv008

73. Zakeri, S. (2019). Ranking based on optimal points multi-criteria decision-making method. Grey Systems: Theory and Application, 9(1), 45-69. https://doi.org/10.1108/GS-09-2018-0040

74. Zakeri, S., \& Keramati, M. A. (2015). Systematic combination of fuzzy and grey numbers for supplier selection problem. Grey Systems. Theory and Application, 5(3), 313-343. https://doi.org/10.1108/GS-03-2015-0008

75. Zakeri, S., Yang, Y., \& Hashemi, M. (2019). Grey strategies interaction model. Journal of Strategy and Management, 12(1), 30-60. https://doi.org/10.1108/JSMA-06-2018-0055

76. Zavadskas, E. K., Kaklauskas, A., \& Kvederyte, N. (2001). Multivariant Design and Multiple Criteria Analysis of a Building Life Cycle. Informatica, Lith. Acad. Sci., 12(1), 169-188. http://doi.org/10.3233/INF-2001-12111

77. Zavadskas, E. K., Kaklauskas, A., \& Sarka, V. (1994). The new method of multicriteria complex proportional assessment of projects. Technological and Economic Development of Economy, 1(3), 131-139.

78. Zavadskas, E. K., Kaklauskas, A., Banaitis, A., \& Kvederyte, N. (2004). Housing credit access model: The case for Lithuania. European Journal of Operational Research, 155(2), 335-352. https://doi.org/10.1016/S0377-2217(03)00091-2

79. Zavadskas, E. K., Kaklauskas, A., Turskis, Z., \& Tamosaitiene, J. (2009). Multi-attribute decision-making model by applying grey numbers. Informatica, Lith. Acad. Sci., 20(2), 305-320. https:/content.iospress.com/articles/informatica/inf20-2-10

80. Zavadskas, E. K., Kaklauskas, A., Turskis, Z., \& Tamošaitiene, J. (2008). Selection of the effective dwelling house walls by applying attributes values determined at intervals. Journal of Civil Engineering and Management, 14(2), 85-93. http://doi.org/10.3846/13923730.2008.14.3 
81. Zhang, S. F., Liu, S. Y., \& Zhai, R. H. (2011). An extended GRA method for MCDM with interval-valued triangular fuzzy assessments and unknown weights. Computers \& Industrial Engineering, 61(4), 1336-1341. https://doi.org/10.1016/j.cie.2011.08.008

82. Zhang, X., Jin, F., \& Liu, P. (2013). A grey relational projection method for multi-attribute decision making based on intuitionistic trapezoidal fuzzy number. Applied Mathematical Modelling, 37(5), 3467-3477. https://doi.org/10.1016/j.apm.2012.08.012 